Audiology

Neurotology
Audiol Neurotol 2020;25:6-24

DOI: $10.1159 / 000502407$
Received: May 31, 2019

Accepted after revision: July 29, 2019

Published online: September 18, 2019

\title{
Electrical Vestibular Stimulation in Humans: A Narrative Review
}

\author{
Morgana Sluydts $^{\mathrm{a}}$ Ian Curthoys ${ }^{\mathrm{b}}$ Robby Vanspauwen ${ }^{\mathrm{a}}$ Blake Croll Papsin ${ }^{\mathrm{c}}$ \\ Sharon Lynn Cushing ${ }^{c}$ Angel Ramos $^{d}$ Angel Ramos de Miguel $^{d}$ \\ Silvia Borkoski Barreiro ${ }^{d}$ Maurizio Barbara ${ }^{e}$ Manuel Manrique $^{f}$ \\ Andrzej Zarowski ${ }^{\mathrm{a}}$
}

${ }^{a}$ European Institute for Otorhinolaryngology, GZA Hospitals Antwerp, Wilrijk, Belgium; b Vestibular Research Laboratory, University of Sydney, Sydney, NSW, Australia; ' Department of Otolaryngology - Head and Neck Surgery, The Hospital for Sick Children, Toronto, ON, Canada; ${ }^{d}$ Hearing Loss Unit, Otorhinolaryngology, Head and Neck Department, Complejo Hospitalario Universitario Insular Materno Infantil, Las Palmas of Gran Canaria, Spain; eNESMOS Department, ENT Clinic, Sapienza University, Rome, Italy; ${ }^{f}$ Otorhinolaryngology Department, Clinica Universidad de Navarra, Pamplona, Spain

\section{Keywords}

Electrical stimulation · Vestibular implant · Galvanic vestibular stimulation - Vestibular co-stimulation · Humans

\section{Abstract}

Background: In patients with bilateral vestibulopathy, the regular treatment options, such as medication, surgery, and/ or vestibular rehabilitation, do not always suffice. Therefore, the focus in this field of vestibular research shifted to electrical vestibular stimulation (EVS) and the development of a system capable of artificially restoring the vestibular function. Key Message: Currently, three approaches are being investigated: vestibular co-stimulation with a cochlear implant $(\mathrm{Cl})$, EVS with a vestibular implant $(\mathrm{VI})$, and galvanic vestibular stimulation (GVS). All three applications show promising results but due to conceptual differences and the experimental state, a consensus on which application is the most ideal for which type of patient is still missing. Summary: Vestibular co-stimulation with a $\mathrm{Cl}$ is based on "spread of excitation," which is a phenomenon that occurs when the currents from the $\mathrm{Cl}$ spread to the surrounding structures and stimulate them. It has been shown that $\mathrm{Cl}$ activation can indeed result in stimulation of the vestibular structures. Therefore, the question was raised whether vestibular costimulation can be functionally used in patients with bilateral vestibulopathy. A more direct vestibular stimulation method can be accomplished by implantation and activation of a VI. The concept of the VI is based on the technology and principles of the $\mathrm{Cl}$. Different $\mathrm{VI}$ prototypes are currently being evaluated regarding feasibility and functionality. So far, all of them were capable of activating different types of vestibular reflexes. A third stimulation method is GVS, which requires the use of surface electrodes instead of an implanted electrode array. However, as the currents are sent through the skull from one mastoid to the other, GVS is rather unspecific. It should be mentioned though, that the reported spread of excitation in both $\mathrm{Cl}$ and $\mathrm{VI}$ use also seems to induce a more unspecific stimulation. Although all three applications of EVS were shown to be effective, it has yet to be defined which option is more desirable based on applicability and efficiency. It is possible and even likely that there is a place for all three approaches, given the diversity of the patient population who serves to gain from such technologies.

(c) 2019 The Author(s)

Published by S. Karger AG, Basel

\section{KARGER}

E-Mail karger@karger.com www.karger.com/aud
(C) 2019 The Author(s) Published by S. Karger AG, Basel

Karger

Open access

This article is licensed under the Creative Commons AttributionNonCommercial-NoDerivatives 4.0 International License (CC BYNC-ND) (http://www.karger.com/Services/OpenAccessLicense) Usage and distribution for commercial purposes as well as any distribution of modified material requires written permission.
Morgana Sluydts

European Institute for Otorhinolaryngology, ENT Department

Sint-Augustinus Hospital, Oosterveldlaan 24

BE-2610 Wilrijk, Antwerp (Belgium)

E-Mail morgana.sluydts@gza.be 


\section{Introduction}

Vestibular stimulation can be accomplished by several stimulation techniques frequently used for diagnostic or therapeutic purposes. Overall, vestibular stimulation can be divided into two categories: nonphysiological and physiological vestibular stimulation. Electrical vestibular stimulation (EVS) is a nonphysiological approach, which has been studied in the past, mainly for investigating the anatomical and neurophysiological structures and pathways of the vestibular system.

Cohen and Suzuki indicated in the 1960s that eye movements could be evoked by electrically stimulating the ampullary and otolith nerves in animals [Cohen and Suzuki, 1963; Suzuki et al., 1964; Suzuki et al., 1968; Suzuki et al., 1969a, b]. Many other researchers subsequently further investigated the effects of acute EVS in both animal and human models [Tokumasu et al., 1971; Markham and Curthoys, 1972; Goldberg et al., 1984; Minor and Goldberg, 1991; Brönte-Stewart et al., 1994; Kushiro et al., 2000; Zhang et al., 2001; Schneider et al., 2002; Zhang et al., 2002; Goto et al., 2003, 2004; Basta et al., 2005; Uchino et al., 2005]. One important finding of these studies was the evidence for convergence of ampullary and otolith input onto single vestibular neurons in response to both natural and electrical vestibular nerve stimulation [Curthoys and Markham, 1971; Markham and Curthoys, 1972]. Due to this convergence at the brainstem level, the peripheral segregation of the semicircular canal (SCC) and otolith organs is not completely maintained centrally. Moreover, as vestibulo-ocular, vestibulo-spinal, and vestibulo-oculospinal neurons form synapses with the converging primary afferents, the vestibulo-ocular, vestibulo-spinal, and vestibulocollic reflexes (VCRs) can all be activated (each to a greater or lesser extent) in response to selective stimulation of a single vestibular end-organ [Curthoys and Markham, 1971; Markham and Curthoys, 1972; Kushiro et al., 2000; Zhang et al., 2001, 2002; Goto et al., 2004; Uchino et al., 2005; Uchino and Kushiro, 2011].

The inner ear can also be stimulated by galvanic stimuli presented at the mastoid process(es) through surface electrodes [Bos and Jongkees, 1963]. The term "galvanic" originally referred to a direct current signal with a unidirectional flow of the currents [Robinson, 2008; Schils, 2009]. If the stimulus is, however, induced by an alternating voltage or current source, the term "galvanic" no longer applies and the broader term "electrical" should be used [Schils, 2009]. Nonetheless, alternating signals have also been used in galvanic vestibular stimulation (GVS) but in contrast to EVS, the stimulus frequency is much lower and within the physiological vestibular range [Coats, 1972; Hlavacka and Njiokiktjien, 1985; Latt et al., 2003; Gensberger et al., 2016].

Recently, many research groups are investigating the treatment options for patients with incapacitating bilateral vestibular loss, resulting in a renewed interest in EVS. In patients with bilateral vestibulopathy, the regular treatment options, such as medication, surgery, and/or vestibular rehabilitation, do not always suffice [Jacobson and Calder, 2000; Brown et al., 2001; Herdman and Clendaniel, 2007; Herdman et al., 2003; Hall et al., 2004; Herdman et al., 2015]. Sensory substitution with vibrotactile and/or auditory cues has been proposed and investigated as a possible solution but, unfortunately, this approach relies on slow-acting feedback systems, which are not capable of compensating for the fast-acting vestibular system [Krebs et al., 1993; Petersen et al., 1995; Brown et al., 2001; Wall et al., 2001; Zingler et al., 2008; Janssen et al., 2012]. Therefore, the focus in this field of vestibular research shifted to EVS for the development of a system capable of artificially restoring the vestibular function. Three approaches are currently being investigated: vestibular costimulation with a cochlear implant (CI), EVS with a vestibular implant (VI), and GVS. Each approach will be discussed below.

\section{Results}

\section{Vestibular Co-Stimulation by a CI}

Due to the close proximity of the auditory and vestibular structures, cochlear implantation can result in activation of the vestibular afferents. Some patients report vestibular sensations like vertigo or lightheadedness when the CI is turned on [Eisenberg et al., 1982; Coordes et al., 2012]. Other authors have reported nystagmus or subjective sensations of dizziness upon CI activation [Bance et al., 1998; Ito, 1998; Coordes et al., 2012]. Parkes et al. [2017] could even evoke cervical and ocular vestibular-evoked myogenic potentials. Similar levels of stimulation also corrected abnormal perceptions of verticality as measured by the subjective visual vertical in this same clinical population [Gnanasegaram et al., 2016]. Such observations support a "spread of excitation" hypothesis, which is a phenomenon that occurs when the currents from the CI spread to the surrounding vestibular structures and facial nerve, and stimulate them [Rubinstein et al., 1996]. Facial nerve stimulation (FNS), for example, is a known complication of CI use that is characterized by 
Table 1. Effects of a cochlear implant on vestibular function

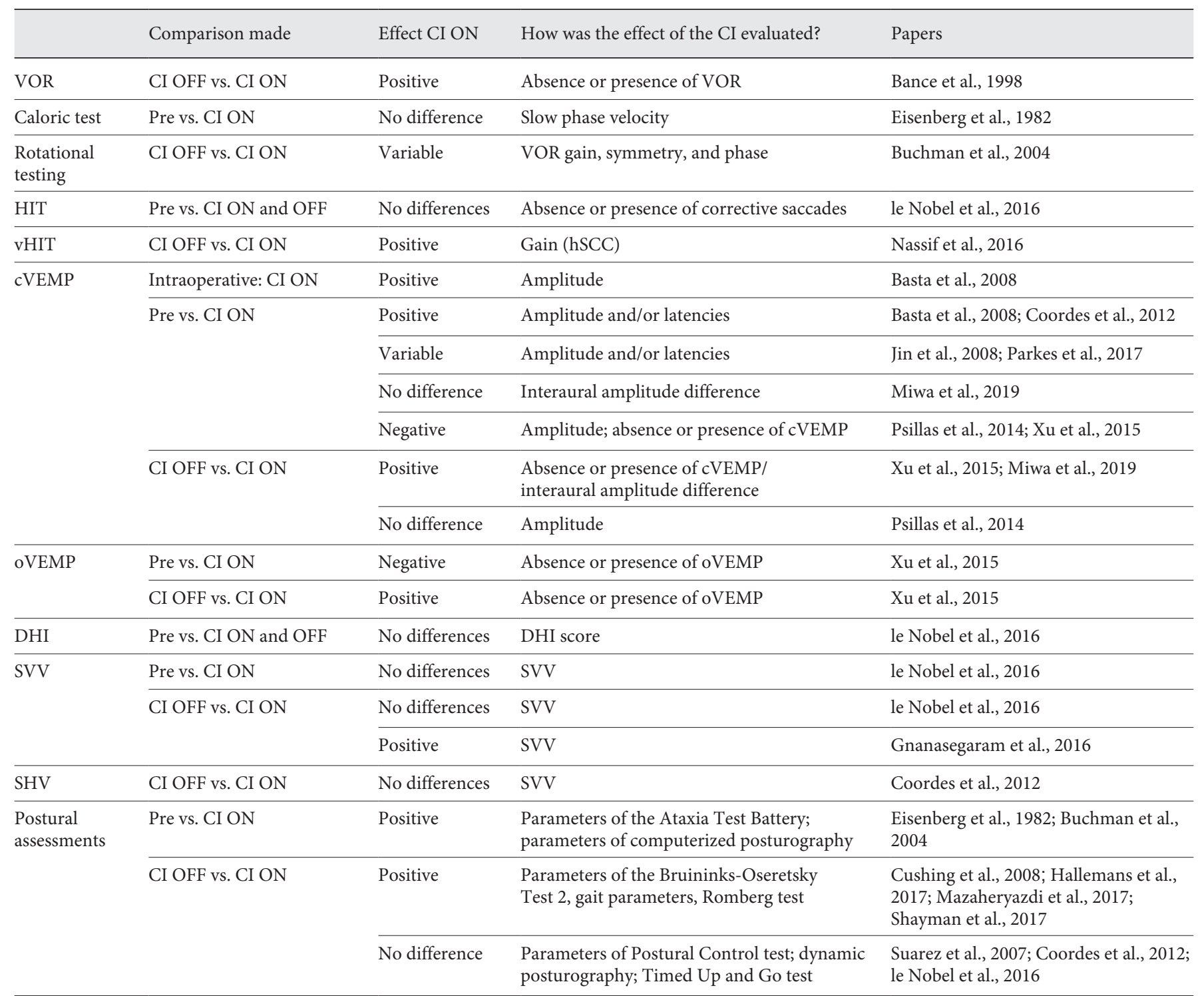

(v)HIT, (video) Head Impulse Test; oVEMP, ocular Vestibular Evoked Myogenic Potential; cVEMP, cervical Vestibular Evoked Myogenic Potential; DHI, Dizziness Handicap Inventory; SVV, Subjective Visual Vertical; SHV, Subjective Haptic Vertical; CI ON/OFF, cochlear implant activated or deactivated; pre, preoperative results (before implantation); hSCC, horizontal semicircular canal; variable, improved, decreased, and/or stable vestibular results; VOR, vestibulo-ocular reflex. Studies investigating the influence of cochlear implantation on the vestibular function without including a test condition with CI activation were not included in this table.

facial twitching or facial sensations [Kelsall et al., 1997; Bigelow et al., 1998; Papsin, 2005; Berrettini et al., 2011]. This FNS can be reduced or avoided by simply adjusting the stimulation parameters of the CI, deactivating certain electrodes, or using perimodiolar electrode arrays (which lie closer to the modiolar wall) in patients at risk of FNS [Kelsall et al., 1997; Polak et al., 2006; Smullen et al., 2005; Berrettini et al., 2011].
In children with sensorineural hearing loss (SNHL) treated with CI, it was suggested that the incidence of FNS is higher than clinically perceivable [Cushing et al., 2006]. Cushing et al. [2006] reported in 39\% (17/44) of children receiving a CI that FNS was only subjectively perceived without having any visually observable facial twitches. Facial twitching was only observable in one fourth of the examined children with CI $(25 \%, 11 / 44)$ even though in 
59\% (26/44) FNS was detected at a subclinical myogenic level using electromyography of the facial musculature.

As the vestibular structures and nerves are also closely located to the cochlear structures and as the membranous labyrinths of the auditory and vestibular systems are connected through the fluid filled ductus reuniens [Rubinstein et al., 1996], current spread to the vestibular system (i.e., "vestibular co-stimulation") is likely.

Many research groups have investigated the possible influences of cochlear implantation and CI use on vestibular function. A major influence on the measured outcomes is whether the CI was activated or deactivated during the testing.

When the CI was in active mode and thus delivering electrical stimulation to the cochlear structures, variable results have been reported [Eisenberg et al., 1982; Buchman et al., 2004; Suarez et al., 2007; Basta et al., 2008; Jin et al., 2008; Coordes et al., 2012; Xu et al., 2015; Gnanasegaram et al., 2016; le Nobel et al., 2016; Nassif et al., 2016; Parkes et al., 2017; Hallemans et al., 2017; Shayman et al., 2017] (Table 1). Comparing preoperative results with postoperative results led to the conclusion that in some cases vestibular and balance function could indeed improve after implantation when the CI was on and active [Eisenberg et al., 1982; Buchman et al., 2004; Basta et al., 2008; Jin et al., 2008; Coordes et al., 2012; Parkes et al., 2017] (Table 1). In other studies, the difference between $\mathrm{CI}$ activation and deactivation was assessed after the implantation [Cushing et al., 2008; Xu et al., 2015; Gnanasegaram et al., 2016; Nassif et al., 2016; Hallemans et al., 2017; Shayman et al., 2017]. The latter postoperative studies confirmed that activating the CI can also lead to improved vestibular and balance outcomes. However, not all results were uniform within and between studies, as well as within and between subjects (Table 1). It is therefore of crucial importance to consider all the differences in the experimental setup when comparing the results of studies investigating the effects of cochlear implantation and CI use.

The main conclusion of the above-described studies is that vestibular and balance function can vary upon CI activation. Consequently, the question is raised whether such "vestibular co-stimulation" can be applied functionally for restoring comorbid vestibular dysfunction in CI recipients and if yes, to what extent.

In some papers, the improved vestibular and balance function observed in CI use has been suggested to arise from the restoration of at times bilateral auditory cues [Hallemans et al., 2017; Shayman et al., 2017]. In a current project (BalanCI project), a combination of vestibular co- stimulation and auditory cues was evaluated. The "BalanCI" is a regular CI processor fitted with an accessory which allows the intracochlear electrode to be activated in response to deviations in position detected by accelerometers and gyroscopes (i.e., head-referenced transcochlear stabilization of balance) [Cushing et al., 2012; $2018 \mathrm{a}, \mathrm{b}]$. This study is conducted in children receiving a $\mathrm{CI}$ and the investigators have reported that there is a significant reduction of the number of falls and a better postural control [Cushing et al., 2012; 2018a, b]. Although the use of the BalanCI currently leads to an auditory percept, it is hypothesized based on previous work [Gnanasegaram et al., 2016; Parkes et al., 2017] that the electrical currents from the stimulus spread towards the vestibular system and contribute to the improved balance.

The hypotheses of vestibular co-stimulation and restored auditory cues probably both contribute to the observed findings in the BalanCI study and in previous literature, as they can both contribute to multisensory integration.

\section{The Human VI}

In order to assess the possibilities of a VI, many animal and computerized models were investigated [for reviews: Della Santina et al., 2010; Lewis, 2016]. A complete overview of the currently available animal VI studies would, however, require (at least) an additional review. Therefore, the appropriate references and conclusions will only be given when necessary for understanding or explaining the results concerning the human VI.

\section{Research Groups}

Currently, four research groups are developing a human VI. For each VI group, a brief update on their progress is provided. In addition to this brief update, the stimulation paradigms and vestibular outcomes are chronologically tabulated in Table 2. An important remark is that, even though in each patient vestibular stimulation was possible to some extent, the results were not always obtainable with all electrodes (e.g., in a patient with an electrode implanted in each of the semicircular canals, not all three electrodes might have been able to successfully stimulate the targeted SCC afferents). Furthermore, different patients often required different stimulation parameters for successfully activating the vestibular reflexes.

Vestibular Pacemaker - Vestibular Neurostimulator. The group from the University of Washington led by Rubinstein, Philips and colleagues developed a vestibular pacemaker, a device for counteracting the symptoms 
Table 2. Detailed overview of the original studies regarding the human vestibular implant

\begin{tabular}{|c|c|c|c|c|c|}
\hline & \multicolumn{5}{|l|}{ Stimulation } \\
\hline & patients & type, time, position & stimulus & modulation & results \\
\hline $\begin{array}{l}\text { Wall et al., } 2007 \\
(n=3)\end{array}$ & UVP/BVP & $\begin{array}{l}\text { Acute: intraop stimulation of the } \\
\text { PAN (EL) }\end{array}$ & $\begin{array}{l}\text { Pulse trains of multiphasic pulses } \\
\text { (repetition rates: } 25-400 \mathrm{pps} \text {; } \\
\text { maximum current amplitude }= \\
1 \mathrm{~mA} \text { ) }\end{array}$ & I & $\begin{array}{l}\text { Not a VI: platinum-iridium solid wire electrode. } \\
\text { Measured outcomes: eVOR (2D VOG) } \\
\text { Results: predominantly vertical eVOR + a robust nystagmus with } \\
\text { SCV large enough to compensate for vertical head movements } \\
\text { (increase in current amplitude = increase in SCV); responses } \\
\text { measurable at } 50 \text { pps; increased SCV with increase in repetition rate } \\
\text { with a maximum at } 200 \text { pps; longer duration run: significant } \\
\text { decrease in response amplitude (erratic trajectory) }\end{array}$ \\
\hline $\begin{array}{l}\text { Guyot et al., 2011a } \\
(n=3)\end{array}$ & UVP (MD) & $\begin{array}{l}\text { Acute: intraop stimulation of the } \\
\text { LAN (EL) }\end{array}$ & $\begin{array}{l}\text { Biphasic pulse train } \\
(400 \mu \mathrm{s} / \text { phase, repetition rate: } \\
200 \mathrm{~Hz})\end{array}$ & l & $\begin{array}{l}\text { Not a VI: } 90 \% \text { platinum - } 10 \% \text { iridium Teflon-coated wire } \\
\text { Measured outcomes: eVOR ( } 2 \text { D VOG) } \\
\text { Results: patient } 3 \text { had a purely horizontal eVOR but patients } 1 \text { and } 2 \\
\text { also had strong vertical components. High intersubject variability } \\
\text { for the current amplitude required for evoking eVOR (facial nerve } \\
\text { stimulation might occur) }\end{array}$ \\
\hline $\begin{array}{l}\text { Guyot et al., 2011b } \\
(n=1)\end{array}$ & BVP & $\begin{array}{l}\text { Acute: postop stimulation of the } \\
\text { PAN (EL) }\end{array}$ & $\begin{array}{l}\text { Biphasic pulse train } \\
\text { ( } 400 \mu \mathrm{s} / \text { phase; repetition rate: } \\
200 \mathrm{pps})\end{array}$ & $\begin{array}{l}\text { Virtual AM: } \\
\text { amplitude: } \\
360 \pm 60 \mu \mathrm{A} \text {; mod. } \\
\text { freq.: } 3 \mathrm{~Hz} \\
\text { Virtual FM: } \\
\text { amplitude: } \\
200 \pm 120 \mathrm{pps}\end{array}$ & $\begin{array}{l}\text { Measured outcomes: eVOR ( } 2 \mathrm{D} \text { VOG) } \\
\text { Results: } \\
\text { Acute stimulation (no modulation) } \\
\text { Vestibular threshold: } 300 \mu \mathrm{A} \\
\text { Suprathreshold stimulation: high-frequency sound and intensity- } \\
\text { dependent dizziness } \\
\text { Baseline adaptation: successive ON-OFF cycling reduces duration of } \\
\text { nystagmic response progressively } \\
\text { After-effect (i.e., change of nystagmus direction when device is } \\
\text { turned off after a continuous stimulation period) } \\
\text { Motion modulation: AM and FM evoke similar responses but larger } \\
\text { amplitudes are observed with AM }\end{array}$ \\
\hline $\begin{array}{l}\text { Guinand et al., } 2011 \\
(n=1)\end{array}$ & BVP & $\begin{array}{l}\text { Postop: acute and intermittent } \\
\text { stimulation of the PAN (EL) }\end{array}$ & $\begin{array}{l}\text { Biphasic pulse train } \\
\text { ( } 400 \mu \mathrm{s} / \text { phase; repetition rate: } \\
200 \mathrm{pps})\end{array}$ & 1 & $\begin{array}{l}\text { Measured outcomes: } \mathrm{eVOR} \text { ( } 2 \mathrm{D} \text { VOG) } \\
\text { Results: repeated ON-OFF cycling of the VI resulted in a shortening } \\
\text { of adaptation time; progressive increase of device deactivation time } \\
\text { shows that beneficial adaptation effect decreases and returns to its } \\
\text { original state after } 18 \mathrm{~h} \text { without electrical stimulation }\end{array}$ \\
\hline $\begin{array}{l}\text { van de Berg et al., } 2012 \\
(n=1)\end{array}$ & BVP & $\begin{array}{l}\text { Acute: intraop stimulation of the } \\
\text { LAN/SAN/PAN (IL) }\end{array}$ & $\begin{array}{l}\text { Biphasic pulse train } \\
(200 \mu \mathrm{s} / \text { phase; repetition rate: } \\
200 \mathrm{pps}) \\
10 \mathrm{~s} \text { pulse train duration with } 0.5 \mathrm{~s} \\
\text { on/off periods }\end{array}$ & 1 & $\begin{array}{l}\text { Not a VI: monopolar electrode } \\
\text { Modified ampullar approach: safe technique to access the ampullae } \\
\text { and VOR is evocable. } \\
\text { Measured outcomes: eVOR ( } 2 \mathrm{D} \text { VOG) } \\
\text { Results: tonic eye deviation elicited at } 700 \mu \mathrm{A} \text { in all } 3 \text { ampullae } \\
\text { (maximum vertical and horizontal amplitudes ranging from } 6.6- \\
19^{\circ} \text { ); stopping the stimulation results into a return of the eye to the } \\
\text { starting point; the horizontal component during SAN stimulation } \\
\text { was delayed }(5 \mathrm{~s}) \text { in comparison with the vertical component }\end{array}$ \\
\hline $\begin{array}{l}\text { Phillips et al., } 2013 \\
(n=4)\end{array}$ & UVP (MD) & $\begin{array}{l}\text { Acute: postop stimulation of } \\
\text { perilymphatic space adjacent to } \\
\text { the ampulla (ISCC, aSCC, pSCC) }\end{array}$ & $\begin{array}{l}2 \text {-s trains of constant-frequency } \\
(300 \mathrm{pps}) \text {, constant-current biphasic } \\
\text { pulses ( } 100 \mu \mathrm{s} / \text { phase; IPG of } 8 \mu \mathrm{s})\end{array}$ & & $\begin{array}{l}\text { Measured outcomes: EEM (2D VOG); postural responses } \\
\text { (computerized posturography). } \\
\text { Results: } \\
\text { EEM: SPV of resultant eye movements: primarily in plane of } \\
\text { stimulated ampulla with smaller off-plane eye components } \\
\text { Postural responses: sway responses were evocable in all SCCs (eyes } \\
\text { open and closed); modulation of the stimulation current modulated } \\
\text { the amplitude of the postural response; all subjects had a significant } \\
\text { increase in sway variance when vision was suppressed; poor } \\
\text { relationship between SPV (in dark) and postural responses (eyes } \\
\text { closed) }\end{array}$ \\
\hline $\begin{array}{l}\text { Perez Fornos et al., } 2014 \\
(n=3)\end{array}$ & BVP & $\begin{array}{l}\text { Acute: postop stimulation of the } \\
\text { LAN (IL) }\end{array}$ & $\begin{array}{l}\text { Biphasic pulse train } \\
\text { ( } 200 \mu \mathrm{s} / \text { phase; repetition rate: } \\
400 \mathrm{pps})\end{array}$ & $\begin{array}{l}\text { Motion induced } \\
\text { AM (chair } \\
\text { frequency: } 0.1 \text {, } \\
0.25,0.5,1 \text {, and } 2 \\
\text { Hz; mod. depth: } 50 \\
\text { and } 75 \% \text { of DR) }\end{array}$ & $\begin{array}{l}\text { Measured outcomes: eVOR (2D VOG) } \\
\text { Results: motion induced AM: the eVOR was evocable, especially at } 1 \\
\text { and } 2 \mathrm{~Hz} \text { rotation frequencies; the LAN stimulation induced a } \\
\text { horizontal eVOR. VOR was significantly higher during device } \\
\text { activation (up to } 79 \% \text { of normal VOR); no significant differences } \\
\text { between these modulation depths }\end{array}$ \\
\hline $\begin{array}{l}\text { Pelizzone et al., } 2014 \\
(n=3)\end{array}$ & BVP & $\begin{array}{l}\text { Acute: postop stimulation of } \\
\text { LAN/SAN/PAN (IL or EL) }\end{array}$ & $\begin{array}{l}\text { Biphasic pulse train } \\
\text { ( } 400 \mu \mathrm{s} / \text { phase; repetition rate: } \\
200 \mathrm{pps})\end{array}$ & $\begin{array}{l}\text { Motion induced } \\
\text { AM (sinusoidal } \\
30^{\circ} / \text { s peak angular } \\
\text { velocity at } 1 \text { and } 2 \\
\mathrm{~Hz} \text { ) }\end{array}$ & $\begin{array}{l}\text { Measured outcomes: eVOR (rotatory chair testing) } \\
\text { Results: significant increase in VOR gain when VI is activated; the } \\
\text { gain increased significantly when the modulation depth increased; } \\
\text { similar results were found at both rotation frequencies ( } 1 \text { and } 2 \mathrm{~Hz} \text { ); } \\
\text { the results are suggestive for multisensory integration processes } \\
\text { (PAN + whole-body rotation in yaw-plan: vertical VOR-axis shifted } \\
\text { towards horizontal) }\end{array}$ \\
\hline
\end{tabular}


Table 2 (continued)

\begin{tabular}{|c|c|c|c|c|c|}
\hline & \multicolumn{5}{|l|}{ Stimulation } \\
\hline & patients & type, time, position & stimulus & modulation & results \\
\hline $\begin{array}{l}\text { Golub et al., } 2014 \\
(n=1)\end{array}$ & UVP (MD) & $\begin{array}{l}\text { Acute: intra- and postop of } \\
\text { perilymphatic space adjacent to } \\
\text { the ampulla (ISCC, aSCC, pSCC) }\end{array}$ & $\begin{array}{l}\text { EEM: } 2 \text {-s pulse trains of constant } \\
\text { current and frequency ( } 300 \text { or } \\
600 \mathrm{pps} \text { Also, biphasic pulses } \\
(100 \mu \mathrm{s} / \text { phase; IPG of } 8 \mu \mathrm{s}) \\
\text { (monopolar) } \\
\text { vECAPS: forward masking } \\
\text { paradigm }\end{array}$ & & $\begin{array}{l}\text { Measured outcomes: vECAPs (NRT; intra- and postop) and EEM } \\
\text { (2D VOG; postop) } \\
\text { Results: } \\
\text { vECAPs: } \\
\text { Intraop: adequate vECAPs: aSCC and ISCC, not from pSCC. } \\
2 \text { weeks postop: vECAPs still present at aSCC and ISCC. } \\
63 \text { weeks postop: vECAPs less pronounced for ISCC and aSCC. } \\
\text { EEM: } \\
\text { Electrode stimulation in } 2 / 3 \text { SCCs: EEM evocable (not in pSCC) } \\
\text { Over time, stimulation thresholds increased. } \\
\text { Increasing current: higher SPV } \\
\text { Doubling pulse frequency (from } 300 \text { to } 600 \text { pps): slightly higher } \\
\text { SPV } \\
63 \text { weeks postop: no longer EEM evocable with aSCC } \\
\text { Subjective sensations: } h S C C \\
\text { lower currents: sense of rolling to the right } \\
\text { higher currents: rightward yaw rotation (amplitude and velocity } \\
\text { increased with increased current) } \\
\text { Subjective sensations: aSCC: movement down and to the left } \\
\text { Subjective sensations: } p S C C \text { : sense of vertigo at early postoperative } \\
\text { time points } \\
\text { Overall: never nauseated or unsteady }\end{array}$ \\
\hline
\end{tabular}

\begin{tabular}{lllll}
\hline $\begin{array}{l}\text { van de Berg et al., 2015 } \\
(n=7)\end{array}$ & BVP & Acute: postop stimulation of & Biphasic pulse train & Virtual AM (mod. \\
& LAN/SAN/PAN (IL or EL) & $400 \mu \mathrm{s} / \mathrm{phase}$; repetition rate: & $\begin{array}{l}\text { depth: 50 or 75\% of } \\
\text { DR; } 3 \text { mod. freq.: } \\
\end{array}$ \\
& & & $0.5,1$, and $2 \mathrm{~Hz})$
\end{tabular}

Overall: never nauseated or unsteady

Measured outcomes: eVOR (2D VOG)

Results:

eVOR: intersubject variability; clear frequency-dependent behavior

for LAN, PAN, and SAN stimulation (in general: increase in modulation frequency $=$ increase in peak eye velocity with a maximum at $2 \mathrm{~Hz}$ ); however, one patient showed opposite behavior (PAN)

Comparison natural VOR and eVOR: similar frequency-dependent behavior between natural VOR and eVOR; the natural VOR angle was close to horizontal while the eVOR angle was almost vertical; both the eVOR and natural VOR show very little adaptation

\begin{tabular}{|c|c|c|c|c|}
\hline $\begin{array}{l}\text { Guinand et al., 2015b } \\
(n=11)\end{array}$ & BVP & $\begin{array}{l}\text { Long-term follow-up of acute } \\
\text { stimulation after baseline } \\
\text { adaptation (LAN/SAN/PAN } \\
\text { [IL or EL]) }\end{array}$ & $\begin{array}{l}\text { Biphasic pulse train } \\
(400 \mu \text { s/phase; repetition rate: } \\
200 \text { pps) }\end{array}$ & $\begin{array}{l}\text { Virtual AM (mod. } \\
\text { freq: } 3 \mathrm{~Hz} \text {; mod. } \\
\text { depth: } 75 \% \text { of DR) }\end{array}$ \\
\hline
\end{tabular}

Measured outcomes: EEM (2D VOG), Visual Acuity (VA test), evoked perceptions (subjective reports)

Results:

EEM: dynamic range: high intersubject and interelectrode variability. Variable range of EEM (based on SPV)

- Average SPV (SD): $\mathrm{PAN}=8.70^{\circ} / \mathrm{s}(7.64) ; \mathrm{LAN}=13.03^{\circ} / \mathrm{s}(12.53)$; $\mathrm{SAN}=11.90^{\circ} / \mathrm{s}(6.65)$

- Average axis (SD): $\mathrm{PAN}=70.59^{\circ}(10.06) ; \mathrm{LAN}=50.56^{\circ}(23.30)$; SAN $=65.44^{\circ}(15.84)$

- Large misalignment in 4 LAN electrodes and 1 SAN electrode Visual acuity $(n=9)$ : stimulation of 7 PAN and 4 SAN electrodes Visual acuity $(n=9)$ : stimulation of 7 PAN
induced a significant loss of visual acuity induced a significant loss of visual acuity intensity

- PAN: none, vertigo, rotational sensation, sound, "tickling" sensation, vibration, eyes moving

- SAN: rotatory sensation, eyes moving, "tickling" sensation, vibration, sound, pressure

- LAN: needle in ear, rotatory sensation, "tickling" sensation, "current-flow" sensation, sound, pressure

\begin{tabular}{|c|c|c|c|c|c|}
\hline $\begin{array}{l}\text { Phillips et al., } 2015 \\
(n=4)\end{array}$ & UVP (MD) & $\begin{array}{l}\text { Acute (intraop) and intermittent } \\
\text { (postop) stimulation of } \\
\text { perilymphatic spaces of SCCs }\end{array}$ & $\begin{array}{l}\text { vECAPs: forward masking } \\
\text { paradigm } \\
\text { EEM: } \\
\text { 2-s pulse trains of biphasic pulses } \\
\text { (constant pulse rate and amplitude; } \\
100 \mu \text { s/phase; } 8 \mu \mathrm{s} \mathrm{IPG)} \\
\text { pulse amplitude } \leq 400 \mu \mathrm{A}\end{array}$ & I & $\begin{array}{l}\text { Measured outcomes: vECAPs (NRT), EEM (2D VOG), and } \\
\text { perceptions (subjective reports) } \\
\text { Results: } \\
\text { vECAPs: used for electrode placement } \\
\text { EEM - acute: EEM are evocable. SPV increased with increased } \\
\text { current amplitude } \\
\text { EEM - intermittent: decrease or fluctuations in SPV } \\
\text { Perceptions: high frequency vibration in } 2 \text { patients with increased } \\
\text { current amplitude; pain was only observed only during higher } \\
\text { currents; perceived rotation was consistent with the stimulated SCC } \\
\text { and side }\end{array}$ \\
\hline $\begin{array}{l}\text { Nguyen et al., } 2016 \\
(n=4)\end{array}$ & BVP & $\begin{array}{l}\text { Acute: postop stimulation of } \\
\text { LAN/SAN/PAN (IL or EL) }\end{array}$ & $\begin{array}{l}\text { Biphasic pulse train } \\
\text { ( } 400 \mu \mathrm{s} / \text { phase; repetition rate: } \\
200 \mathrm{pps})\end{array}$ & $\begin{array}{l}\text { Virtual AM (Mod. } \\
\text { freq: } 1 \mathrm{~Hz} \text {; mod. } \\
\text { depth: medium and } \\
\text { high) } \\
\text { Virtual FM (mod. } \\
\text { freq: } 1 \mathrm{~Hz} \text {; Mod. } \\
\text { depth: medium, } \\
\text { high, and } 2 \times \text { high) }\end{array}$ & $\begin{array}{l}\text { Measured outcomes: eVOR ( } 2 \mathrm{D} \text { VOG) } \\
\text { Results: } \\
\text { Single mode modulation: AM significantly higher responses than } \\
\text { FM. No consistent impact of modulation depths on either AM or } \\
\text { FM } \\
\text { Comodulation (neural network model): stronger results than with } \\
\text { AM or FM separately }\end{array}$ \\
\hline $\begin{array}{l}\text { McCrum et al., } 2016 \\
(n=2)\end{array}$ & BVP & & & & $\begin{array}{l}\text { Measured outcomes: gait } \\
\text { Results: stride length and stride time increased: Especially when } \\
\text { positive AM modulation was applied (i.e., EEM in opposite } \\
\text { direction to head movement) }\end{array}$ \\
\hline $\begin{array}{l}\text { Guinand et al., } 2016 \\
(n=6)\end{array}$ & BVP & $\begin{array}{l}\text { Acute: postop stimulation of } \\
\text { SAN/PAN (IL or EL) }\end{array}$ & $\begin{array}{l}\text { Biphasic pulse train } \\
(200 \mu \mathrm{s} / \text { phase; repetition rate: } \\
400 \mathrm{pps})\end{array}$ & $\begin{array}{l}\text { Motion induced } \\
\text { AM (mod. depth: } \\
85 \% \text { of DR) }\end{array}$ & $\begin{array}{l}\text { Measured outcomes: visual acuity } \\
\text { Results: VI activated: visual acuity improved upon activation (close } \\
\text { to normal). Improvement disappeared in placebo condition }\end{array}$ \\
\hline
\end{tabular}

\section{Electrical Vestibular Stimulation in} Humans 
Table 2 (continued)

\begin{tabular}{|c|c|c|c|c|c|}
\hline & \multicolumn{5}{|l|}{ Stimulation } \\
\hline & patients & type, time, position & stimulus & modulation & results \\
\hline $\begin{array}{l}\text { Nguyen et al., } 2017 \\
(n=4)\end{array}$ & BVP & $\begin{array}{l}\text { Acute and chronic stimulation } \\
\text { (IL or EL) }\end{array}$ & $\begin{array}{l}\text { Biphasic pulses }(59 \mu \mathrm{s} / \\
\text { phase; IPG: } 2,1 \mu \mathrm{s}) \\
\text { Alternating polarity paradigm } \\
\text { (artefact reduction) }\end{array}$ & 1 & $\begin{array}{l}\text { Measured outcomes: ECAPS, vECAPS, and mixed CAPs (NRT) } \\
\text { Results: cochlear eCAPs > mixed eCAPs > vestibular eCAPs; no } \\
\text { correlations between stimulating and recording electrode distance, } \\
\text { voltages used, and latencies }\end{array}$ \\
\hline $\begin{array}{l}\text { Guinand et al., } 2017 \\
(n=3)\end{array}$ & BVP & $\begin{array}{l}\text { Acute: postop stimulation of } \\
\text { LAN/SAN/PAN (IL or EL) }\end{array}$ & $\begin{array}{l}\text { Biphasic pulse train } \\
(200 \mu \mathrm{s} / \text { phase; repetition rate: } \\
400 \mathrm{pps}) \text {; pseudomonopolar }\end{array}$ & $\begin{array}{l}\text { Motion induced } \\
\text { AM }\end{array}$ & $\begin{array}{l}\text { Measured outcomes: high-frequency eVOR (vHIT) } \\
\text { Results: } 3 / 5 \text { tested electrodes: aVOR gain increased monotonically } \\
\text { with increased stimulation strength of head impulse in plane of } \\
\text { implanted SCC; Gains ranging from } 0.4 \text { to values above } 1 \text {. A } \\
\text { "reversed" aVOR: inversed stimulation paradigms; gain excitatory } \\
\text { head impulses were higher than gain of inhibitory head impulses; } \\
\text { improvements of the aVOR gain were accompanied by a } \\
\text { concomitant decrease of corrective saccades; however, variable } \\
\text { results depending on which SCC electrode and which subject were } \\
\text { stimulated }\end{array}$ \\
\hline $\begin{array}{l}\text { van de Berg } \\
\text { et al., } 2017 \\
(n=4)\end{array}$ & BVP & $\begin{array}{l}\text { Acute: postop stimulation of } \\
\text { LAN/SAN/PAN (IL) }\end{array}$ & $\begin{array}{l}\text { Biphasic pulse train } \\
(200 \mu \mathrm{s} / \text { phase; repetition rate: } \\
400 \mathrm{pps})\end{array}$ & $\begin{array}{l}\text { Virtual and motion } \\
\text { induced AM (mod. } \\
\text { freq.: } 1 \mathrm{~Hz} \text {; mod. } \\
\text { depth: } 50 \text { to } 90 \% \\
\text { of DR) }\end{array}$ & $\begin{array}{l}\text { Measured outcomes: virtual and motion-induced eVOR (rotatory } \\
\text { chair) } \\
\text { Results: nonlinear interaction between residual natural function and } \\
\text { eVOR }\end{array}$ \\
\hline $\begin{array}{l}\text { Perez Fornos et al., } \\
2017 \\
(n=5)\end{array}$ & BVP & $\begin{array}{l}\text { Acute: postop stimulation of } \\
\text { LAN/SAN (IL) }\end{array}$ & $\begin{array}{l}100 \text { trials of single, cathodic-first, } \\
\text { biphasic, charge balanced pulses } \\
\text { (repetition rate: } 5 \text { pps) }\end{array}$ & l & $\begin{array}{l}\text { Measured outcomes: VCR (ecVEMPs) } \\
\text { Results: ecVEMPs elicited in } 5 \text { patients } \\
\text { Average latencies (SD): latency P1 peak = } 9.8 \mathrm{~s}(1.0) \text {; latency N1 } \\
\text { peak }=16.9 \mathrm{~s}(1.7)\end{array}$ \\
\hline $\begin{array}{l}\text { Ramos de Miguel } \\
\text { et al., } 2017 \\
(n=4)\end{array}$ & UVP (MD) & $\begin{array}{l}\text { Acute: intraop stimulation of the } \\
\text { vestibule }\end{array}$ & $\begin{array}{l}\text { Single biphasic pulses } \\
(57 \mu \text { s pulses, } 25 \mu \mathrm{s} / \text { phase, } \\
10 \mu \mathrm{s} \text { IPG })\end{array}$ & 1 & $\begin{array}{l}\text { Measured outcomes: vECAPs (VRT) and utriculo-ocular reflex } \\
\text { (eoVEMPs) } \\
\text { Results: otolith implant } \\
\text { - } v E C A P S \text { : obtained in } 10 / 12 \text { electrodes } \\
\text { - eoVEMPs: recorded when vECAP was present }(n=10) \text { (latency N1 } \\
\text { peak: } 400 \mu \text { s; latency P1 peak: } 800 \mu s ; \text { N1P1 peak-to-peak amplitude: } \\
71.15 \mu \mathrm{V} \text { ) }\end{array}$ \\
\hline $\begin{array}{l}\text { Johns Hopkins group, no } \\
\text { official paper published yet } \\
\text { (Conference abstracts/ } \\
\text { presentations: } \\
\text { Boutros et al., 2018a-c; } \\
\text { Chow, 2018a; Chow et al., } \\
\text { 2018a; Della Santina; } \\
\text { 2018a, b) }\end{array}$ & $\begin{array}{l}\text { BVP - } \\
\text { tPTA up to } \\
70 \mathrm{~dB} \text { HL }\end{array}$ & $\begin{array}{l}\text { Chronic IL stimulation with } \\
\text { longitudinal follow-up }\end{array}$ & Biphasic pulse trains & $\begin{array}{l}\text { Motion } \\
\text { modulation or } \\
\text { constant electrical } \\
\text { stimulation }\end{array}$ & $\begin{array}{l}\text { Measured outcomes: VOR }(0.5-5 \mathrm{~Hz} \text { passive head or whole-body } \\
\text { rotation), VCR, hearing (PTA and speech audiometry), posture, } \\
\text { gait, QoL } \\
\text { Results: } \\
\text { eVOR: evocable and mostly aligned with stimulated SCC. Motion } \\
\text { modulation > constant stimulation. Motion perception thresholds } \\
\text { lower than eVOR thresholds } \\
\text { VCR: evocable } \\
\text { Hearing: sufficient for unaided communication } \\
\text { Postural outcomes: improved posture and gait Re-initiation of daily } \\
\text { life activities and improved; QoL; one patient experiences less im- } \\
\text { provement than the others (determined by the questionnaires) }\end{array}$ \\
\hline
\end{tabular}

$n$, number of patients included in the respective study; UVP/BVP, uni- or bilateral vestibulopathy; intra-op/postop, intra-operative/postoperative testing; PAN/LAN/SAN, posterior, lateral, superior ampullar nerve; IL/EL, intra- or extra-labyrinthine surgical approach; pps, pulses per second; 2D VOG, two-dimensional video oculography; (e)VOR, (electrically evoked) vestibulo-ocular reflex; VI, vestibular implant; SCV, slow component velocity; MD, Ménière's disease; AM/FM, amplitude or frequency modulation; mod. freq., modulation frequency; (1/a/p) SCC, (lateral, anterior, or posterior) semicircular canal; IPG, interphase gap; EEM, electrically evoked eye movements; SPV, slow phase velocity; SD, standard deviation; mod. depth, modulation depth; DR, dynamic range; (v)ECAPs, (vestibular) electrically evoked compound action potentials; NRT, neural response telemetry; vHIT, video head impulse test; ecVEMPs, electrically evoked cervical vestibular evoked myogenic potentials; VCR, vestibulocollic reflex; PTA, pure tone audiometry; QoL, quality of life; empty cell, not specified/mentioned in paper.

evoked by a Ménière's disease (MD) attack [Rubinstein et al., 2010; Nie et al., 2011, 2013; Bierer et al., 2012; Rubinstein et al., 2012; Golub et al., 2014] (Table 2). The design of this vestibular pacemaker was based on a commercially available CI which was modified for semicircular canal afferent stimulation. The vestibular pacemaker consisted of two extracochlear reference electrodes (the plate and the ball electrode) and three stimulating SCC electrode arrays (each containing three electrode contacts). The possibilities of this device were investigated in animal models first, which led to the initiation of a human trial.

In this human study, the SCC electrode arrays were implanted in the perilymphatic space of the SCCs in order to stimulate the preferred semicircular canal and its af- ferents. The choice for this surgical approach was based on the idea that an intact endolymphatic compartment would increase the likelihood of preserving the residual vestibular function [Rubinstein et al., 2012].

The hypothesis behind this vestibular pacemaker was to counteract the vestibular symptoms accompanying an attack in patients with incapacitating MD [Golub et al., 2014; Phillips et al., 2015]. Unfortunately, only the results of 1 patient with a mild MD attack lasting $1 \mathrm{~h}$ were reported [Golub et al., 2014]. During the attack (which occurred while the patient was at home), the patient cycled through the stimulation programs of the modified CI. Each program entailed an increase in current intensity steps of $25 \mu \mathrm{A}$. The first program $(150 \mu \mathrm{A}$ at 600 pulses 
per second [pps]) suppressed the MD-induced symptoms but the second program $(175 \mu \mathrm{A}$ at $600 \mathrm{pps})$ worsened the vertigo, as did turning the device off during the MD attack. These results support the hypothesis of a functional vestibular pacemaker designed for counteracting the vestibular symptoms/complaints that are still perceivable due to residual vestibular function. Unfortunately, the vestibular implantation led to complete loss of all vestibular and auditory function, with only limited auditory recovery [Golub et al., 2014; Phillips et al., 2015], which limits the functional applicability of this device.

The investigators of this research group further explored the possibilities of their device during acute and intermittent experiments inside the laboratory [Phillips et al., 2013, 2015]. The electrical stimulation of the semicircular canal afferents resulted in postural responses (e.g., whole-body sway), subjective sensations (e.g., roll, yaw, rotation), eye movements (or the electrically evoked vestibulo-ocular reflex $[\mathrm{eVOR}])$, and vestibular electrically evoked compound action potentials (vECAPs) in several cases [Phillips et al., 2013, 2015] (Table 2). Similar to the auditory ECAPs in CIs, the vECAPs can be used for confirming the electrode placement. Longitudinal intermittent stimulation with this vestibular neurostimulator, however, showed decreased vECAPs in some of the electrodes and decreased or fluctuating slow-phase velocities of the eVOR. Phillips et al. [2015] suggested that perhaps the sensitivity of the individual afferents to electrical stimulation changed over time, resulting in a changed neural signal [Golub et al., 2014; Phillips et al., 2015].

The device used in the aforementioned human studies did not include an intracochlear electrode array. As patients with combined cochleovestibular loss could benefit from a combined cochleovestibular stimulator, the investigators modified the design of the VI so that an intracochlear electrode array with 16 electrode contacts was also available. As the CI used for vestibular modification originally had 22 electrode contacts, the amount of electrode contacts per SCC electrode array was reduced to two [Phillips et al., 2018]. With this newly designed vestibular neurostimulator the relationship between the parameters of electrical stimulation and the eVOR in rhesus monkeys was examined. This animal study indicated that increasing the frequency and amplitude parameters in constant biphasic pulse trains resulted in an increase in slow-phase velocity [Phillips et al., 2018]. To date, three humans have been implanted with this new design with results and outcomes in review for publication [personal communication: Rubinstein J., April 30, 2019].

Electrical Vestibular Stimulation in Humans
Vestibulocochlear Implant. A second group of researchers developing a VI is the Maastricht-Geneva group. In an initial proof-of-concept study, it was shown that the electrical stimulation of the ampullary nerve with separate wire electrodes could successfully evoke eye movements or the eVOR during intraoperative experiments (Table 2) [Wall et al., 2007; Guyot et al., 2011a]. Based on these preliminary results, a CI was modified and implanted in the vicinity of the afferents of the SCCs for initiating the SCC implant studies. The design of this vestibulocochlear implant is also based on a commercially available $\mathrm{CI}$ and provides $1-3$ vestibular electrodes for the SCCs, together with an intracochlear electrode array for the cochlea (with a minimum of 9 electrode contacts) [Guyot et al., 2011a; van de Berg et al., 2012; Guinand et al., 2015a]. The housing of this vestibulocochlear implant is used as the reference electrode.

Until now (April 2019), 13 patients with bilateral vestibular areflexia have been implanted following an extraor intra-labyrinthine surgical technique (cf. infra). All of these patients were either deaf or showed profound SNHL. Therefore, reliable interpretation of hearing preservation was not possible [Perez Fornos et al., 2017]. Stimulation with this vestibulocochlear implant resulted in the eVOR, vECAPs, and perceptual sensations. For the eVOR, frequency-dependent behavior was detected for a broad frequency range and was found to be similar to the natural frequency dependency of the angular vestibuloocular reflex (aVOR) [van de Berg et al., 2015; Guinand et al., 2017]. Furthermore, the VCR could be evoked and improvements of the dynamic visual acuity and gait were established [Guyot et al., 2011b; Perez Fornos et al., 2014; Pelizzone et al., 2014; van de Berg et al., 2015; Guinand et al., 2015b, 2016; McCrum et al., 2016; Nguyen et al., 2016, 2017; Perez Fornos et al., 2017; van de Berg et al., 2017] (Table 2 ). The variability in artificially evoked vestibular responses can be partially explained by the neural convergence as both the artificially and naturally stimulated neurons can provide information to the convergent neurons [Curthoys and Markham, 1971; Markham and Curthoys, 1972; Kushiro et al., 2000; Zhang et al., 2001, 2002; Goto et al., 2004; Uchino et al., 2005, 2011].

In a recent study, the investigators of the MaastrichtGeneva group examined the effect of combining the naturally evoked aVOR (generated by residual vestibular function) with its electrically induced equivalent, the eVOR (presented at 400 pps) [van de Berg et al., 2017]. The general conclusion was that the output of the eVOR and the aVOR combine in a nonlinear way, so that the strongest component (either the eVOR or the aVOR) de-

Audiol Neurotol 2020;25:6-24 
fines the characteristics of the combined VOR. Inverting the stimulation paradigm by changing the orientation of the gyroscope resulted in a reduced combined VOR, as the artificial input (partially) counteracted the residual natural function. It was therefore suggested that the vestibulocochlear implant might be capable of acting like a vestibular pacemaker, a concept that was earlier introduced by the University of Washington group (cf. supra) [Golub et al., 2014; van de Berg et al., 2017]. So far, the VI was only activated inside the laboratory and in the hospital setting.

Multichannel VI. The third group of VI investigators from Johns Hopkins has developed a multichannel VI (MVI) [Hageman et al., 2016; Della Santina, 2018a]. This MVI has built-in gyroscopes and accelerometers capable of sensing and encoding three-dimensional rotations and linear accelerations [Hageman et al., 2016]. Fifty stimulating electrode contacts are distributed over three electrode shanks: one shank for the saccule (13 electrodes contacts) and the horizontal SCC (8 electrode contacts), one shank for the utricle (13 electrode contacts) and the superior SCC (8 electrode contacts), and one separate shank for the posterior SCC (8 electrode contacts) [Hageman et al., 2016; Della Santina, 2018a]. At the initiation of the human trial in 2016, implantation of electrodes in the human otolith system was not yet approved by the appropriate authorities. Therefore, a modified version of the abovementioned MVI was implanted in 4 patients and the results were obtained with SCC stimulation only [Boutros et al., 2018a]. The investigators have, however, investigated the effects of combined electrical SCC and otolith stimulation in an animal model with chinchillas (cf. infra) [Chow et al., 2018b; Hageman et al., 2018]. Both MVI designs (used in the animal and human studies) did not include an intracochlear electrode array. The researchers attempted and partially succeeded in preserving the hearing in 4 patients with bilateral loss of the SCC functions and pure tone audiometry averages better than $70 \mathrm{~dB}$ HL. In 1 patient, a slight component of low-frequency hearing loss was found and in 2 out of 4 a new high-frequency SNHL was detected, but the speech recognition scores remained stable in all 4 MVI patients [Schoo, 2018; Schoo et al., 2018] (Table 2).

The Johns Hopkins group led by Della Santina and his colleagues were the first to evoke a three-dimensional aVOR with electrical stimulation of more than one SCC [Boutros et al., 2018a-c] (Table 2). Furthermore, the human patients used the device chronically throughout the trial in and outside the clinic for 8 weeks, which is different from the protocols of the aforementioned SCC im- plants in which only brief outside-clinic activations (or none at all) were approved by the local ethics committees [Nguyen et al., 2014; Phillips et al., 2015].

Electrical stimulation of the SCC afferents also resulted in sensations of motion, activation of the VCR, and subjectively and objectively improved postural control and gait [Boutros, 2018b; Chow, 2018a; Chow et al., 2018a; Della Santina, 2018a] (Table 2). These findings can be explained by the neural convergence of the vestibular primary afferents onto single central neurons [Curthoys and Markham, 1971; Markham and Curthoys, 1972; Kushiro et al., 2000; Zhang et al., 2001, 2002; Goto et al., 2004; Uchino et al., 2005, 2011]. It should be considered that current spread due to the close proximity of the vestibular end-organs can be an important contributing factor as well. Furthermore, the multisensory integration and overall neural plasticity probably also contributed to these outcomes as the patients were allowed to use the device in real-life situations outside the clinic. Additionally, the patients were obliged to follow an extensive program of vestibular rehabilitation during the trial. Although the patients had at least 1 year of vestibular rehabilitation without experiencing any functional benefit prior to the trial, the presence of the artificial vestibular input may have been enough for the human brain to integrate it with the natural input provided by the nonvestibular senses. In future research, it is likely that the comparison of VI use with and without vestibular rehabilitation will be made. Furthermore, 2 of the MVI patients had intact pre- and postoperative otolith function, which may have contributed to the postural improvements as well.

An additional observation in this study was that the subjectively reported improvement of the unsteadiness was larger than the objectified outcomes [Della Santina, 2018a].

So far, simultaneous activation of the otolith and SCC electrodes has only been done in animal models [Chow, 2018b, c; Chow et al., 2018b; Hageman et al., 2018] (Table 2). Ocular counter-roll (OCR) responses could be elicited when SCC and otolith stimulation were combined in chinchillas, a response that was expected based on the previous work of Suzuki and colleagues in animal studies [Cohen and Suzuki, 1963; Suzuki et al., 1964, 1968, 1969a, b; Tokumasu et al., 1971; Markham and Curthoys, 1972; Kushiro et al., 2000; Zhang et al., 2001, 2002; Goto et al., 2003, 2004; Uchino et al., 2005, 2011]. Linearly increasing the stimulation parameters resulted in a linear increase in the OCR's amplitude [Chow, 2018c; Hageman et al., 2018]. The electrically evoked OCR approximated the eye
Sluydts et al. 
responses expected during a natural head tilt in chinchillas [Chow, 2018b; Chow et al., 2018b].

The temporal characteristics of the measured eye movements evoked with an otolith electrode were dependent on where the reference electrode was placed. When the reference electrode was positioned in the vicinity (in the common crus) of the stimulating otolith electrode, a slow onset of the response was measured. In contrast, when the reference electrode was placed at a more distant location (in a distant muscle), a quick response onset occurred. A possible explanation can be found in the fundamentals of electrical stimulation. In monopolar stimulation, the reference or return electrode is placed at a distant location. Doing so results in less selective stimulation than can be expected with, for example, bipolar stimulation (i.e., one of the electrodes on the electrode array serves as return/reference electrode while another serves as stimulating electrode). In monopolar stimulation, the position of the reference electrode defines the area that is affected by the electrical currents. Placing the reference electrode far away from the stimulating electrode results in a larger area of neurons being (partially or fully) activated. Therefore, the activation of more (convergent and nonconvergent, regular and irregular) ampullary and otolith afferents that can contribute to the OCR is more likely. A reference electrode positioned closer to the stimulating electrode will result in a smaller area of electrically activated neurons and thus, less afferents that send information to initiate the OCR.

Otolith Implant. In addition to these 3 VI prototypes for SCC stimulation, initial steps have been taken to develop an implant for direct otolith stimulation by a fourth research group from the University of Las Palmas [Ramos de Miguel et al., 2017] (Table 2). So far, vestibular responses were captured during acute intraoperative measurements by temporarily inserting up to 3 apical electrodes of a standard CI in the vestibule. As reference electrode, a plate electrode or a ball electrode was used. This experiment was conducted in 3 patients suffering from definite unilateral MD. These results showed that direct otolith stimulation with single biphasic pulses (57 $\mu \mathrm{s}$ pulses, $25 \mu$ s/phase, $7 \mu$ s interphase gap) evoked vestibular ECAPs and ocular VEMPs. After the experiments, the electrode array was removed from the vestibular system and implanted in the cochlea [Ramos de Miguel et al., 2017].

Basic Principles and Challenges of EVS with a VI

Restoration of Spontaneous Spike Rate. Converting the natural head and body movements into an adequate neu- ral spike pattern requires a spontaneous firing rate that can be up- or downmodulated (i.e., motion modulation) [Hain and Helminski, 2007; Halmagyi and Curthoys, 2007]. The basic principle of a VI is, therefore, to restore this motion modulation as accurately as possible. The first step in this process of artificially restoring the vestibular function is therefore the restoration of the spontaneous firing rate of the vestibular afferents so that motion modulation can be simulated subsequently [Guyot et al., 2016].

The currently available results of human VI trials are obtained with unilaterally implanted SCC implants in patients with bilateral vestibulopathy (BVP) according to the Bárány Society diagnostic criteria [Strupp et al., 2017]. These diagnostic criteria provide very precise guidelines for the function of the semicircular canals but less detailed information regarding utricular and saccular function. Therefore, the patients with a SCC implant may have residual or even normal otolith function (cf. two MVI patients of the Johns Hopkins group). As only SCC implants are currently permanently implanted, the following section will focus on the principles and challenges of electrically stimulating the ampullary nerves in human subjects.

The spike rate pattern of the semicircular canals is based on the push-pull principle in which excitation of one SCC implies inhibition of the coplanar SCC [Precht et al., 1966]. Unfortunately, the current human VI research is limited to unilateral vestibular implantation in BVP patients due to a risk of iatrogenic hearing loss, higher costs, ethical considerations, and the experimental state of the VI [van de Berg et al., 2011; Golub et al., 2014; Della Santina, 2018a]. Due to this limitation, the restoration of the spontaneous firing rate is more challenging, as unilateral stimulation in BVP patients will lead to an artificial asymmetry in the afferents' spike rate. Consequently, nystagmus and possibly also vertigo and/or nausea will be induced at both the onset and offset of the stimulation [Guyot et al., 2011b].

However, experimental evidence shows that continuous stimulation with a constant electrical stimulus (i.e., baseline stimulation) results in reduction and elimination of these unwanted vestibular symptoms within $30 \mathrm{~min}$ (i.e., baseline adaptation to the baseline stimulus) [Guinand et al., 2011; Guyot et al., 2011b]. Turning the device off after baseline adaptation initiates the vertigo and nausea again with a nystagmus beating in the opposite direction [Guinand et al., 2011; Guyot et al., 2011b]. Fortunately, these symptoms, arising in response to the device deactivation, disappear even quicker than the 30-min 
adaptation time required for VI activation [Guinand et al., 2011]. The same phenomenon has been reported earlier in animal studies and was attributed to the central nervous system being more capable of recognizing the known, nonstimulated state of the vestibular system as opposed to the new, electrically stimulated state [Gong and Merfeld, 2002]. Repeatedly turning the VI on and off resulted in a reduced adaptation time for the central nervous system to suppress the responses evoked by the change in stimulation state (both after device activation and deactivation, i.e., dual state adaptation) [Gong and Merfeld, 2002; Guinand et al., 2011; Guyot et al., 2011b]. This reduction in adaptation time is progressively lost when the device is deactivated for longer periods of time (e.g., $1 \mathrm{~h}$ ). After approximately $18 \mathrm{~h}$, the benefit of the rapid on and off cycling is completely lost [Guinand et al., 2011]. These results suggest that daily life activities with a VI (including situations requiring short device deactivation) should be feasible without too much patient discomfort [Guinand et al., 2011; Guyot et al., 2011b; van de Berg et al., 2011]. It should be mentioned, however, that the VI patients might not benefit yet from the VI in activities requiring quick activation and use of the device. Turning the device briefly on for a midnight bathroom break, for example, requires a fast adaptation to the electrical stimulation. Due to this sudden activation, the artificial tone imbalance might even further increase the risk of falling. Moreover, as the patient might be a bit drowsy right after awakening and as the visual conditions are less than optimal (dark room), the fall risk might be even higher.

Motion Modulation. A second prerequisite for EVS is adequate modulation of the electrical input signal, with a motion profile (i.e., so-called "motion modulation"). In BVP patients with a unilateral VI, the restored spontaneous firing rate needs to be up- and downmodulated for mimicking the natural excitatory and inhibitory head movements, respectively [Davidovics et al., 2012; Guyot et al., 2016]. Especially inhibitory responses can be difficult to encode with unilateral electrical stimulation because the downmodulation must be large enough for the brain to interpret this lowering in firing rate as an actual inhibition [Davidovics et al., 2012]. Therefore, the baseline stimulus is usually set at a supraphysiological level, so that the stimulus can be up- and downmodulated symmetrically [Guyot et al., 2016]. However, supraphysiological baseline stimulation has been shown to increase the inhibitory responses but decrease the excitatory responses and moreover, symmetrical motion modulation does not approximate the natural asymmetrical sensitivity of the vestibular system. This might therefore result in less optimal vestibular stimulation [Davidovics et al., 2012]. Nonetheless, as the human vestibular system is more sensitive to excitatory movements, this should not be a functional limitation of the SCC implant.

Motion modulation around a baseline stimulus can be accomplished by pulse frequency modulation, pulse amplitude modulation, or a combination of the two (comodulation). The latter has only been investigated in animal and neural network models so far [Guyot et al., 2011b; Davidovics et al., 2012; Nguyen et al., 2016].

Frequency modulation is most similar to the natural neural coding of the vestibular system and could therefore be expected to be the most effective [Fernandez and Goldberg, 1971]. However, in several studies, amplitude modulation has been shown to be more effective in evoking eye movements than frequency modulation [Guyot et al., 2011b; Perez Fornos et al., 2014; Nguyen et al., 2016]. Davidovics et al. [2012] suggested that this might be explained by a depletion of the synaptic vesicle pool induced by the continuous firing of the recruited afferents during the baseline adaptation. Frequency modulation of the already adapted afferents with the depleted synaptic vesicle pools will result in a limited increase in firing rate of the already recruited afferents whereas amplitude modulation will recruit additional nonadapted afferents. Therefore, the outcomes obtained with amplitude modulation may be better than those achieved with frequency modulation. Nonetheless, improved gain, symmetry, and alignment of the eVOR have been observed in animals during chronic frequency modulation [Lewis et al., 2010]. The animals were free to move around in their cages during these chronic experiments, which probably contributed to the multisensory integration.

Furthermore, the results of animal and neural network models have indicated that the evoked responses with comodulation are even larger than those with amplitude modulation or frequency modulation alone. It is, therefore, suspected that co-modulation combines the effects of amplitude modulation and frequency modulation (i.e., spatiotemporal summation) [Davidovics et al., 2012; DiGiovanna et al., 2016; Nguyen et al., 2016].

Acute or Chronic Stimulation. The abovementioned results of the SCC implant were mostly obtained during acute or intermittent EVS [Golub et al., 2014; Phillips et al., 2015; Nguyen et al., 2017]. Only the Johns Hopkins group has reported on 8-week trials of continuous stimulation and this in both a laboratory setting as well as the home setting of the recipients (cf. supra).

During all human VI studies, similar results were obtained, supporting the feasibility of the SCC implant.
16

Audiol Neurotol 2020;25:6-24 DOI: $10.1159 / 000502407$
Sluydts et al. 
However, intermittent testing showed that certain outcome parameters were less consistent with time and that the stimulation parameters being capable of inducing vestibular responses showed a great inter- and intrasubject variability. As a result, it is not possible (yet) to identify a stimulus most optimal for vestibular stimulation. A more detailed overview of the currently available VI papers is presented in Table 2. No further data regarding additional effects of chronic stimulation is available at the moment (April 2019).

Central Vestibular Convergence in the Vestibular $\mathrm{Nu}$ clei and Multisensory Integration. As mentioned above, SCC stimulation resulted quite often in improved otolithinduced responses. It is likely that these responses are due to a combination of current spread and central convergence of the primary (regular and irregular) vestibular afferents on the second-order vestibular nuclei neurons. As some of the stimulated SCC afferents send action potentials to central convergent neurons, both otolith and SCC components will be represented at a central level [Curthoys and Markham, 1971; Markham and Curthoys, 1972]. The rather unselective nature of the electrical stimuli presented to the SCC afferents may therefore also be responsible for the reported misalignment of the VOR axis [Golub et al., 2014; Guinand et al., 2015a; Boutros, 2018b]. Due to current spread, other nontargeted primary SCC or otolith afferents may be activated and thus further influence the misalignment.

In animal models, the VOR axis misalignment was shown to be significantly reduced within 1 week of chronic electrical stimulation [Dai et al., 2013]. This phenomenon is called cross-axis adaptation, which represents the directional plasticity of the vestibulo-ocular central nervous system. A similar finding was observed in the human VI study of Pelizzone et al. [2014], in which artificial stimulation of the posterior ampullary nerve and a wholebody rotation in the yaw plane were combined. The vertical VOR axis induced by the artificial posterior ampullary nerve stimulation shifted towards horizontal when the patient was rotated in the yaw plane. The horizontal eye movement turned back into a vertical one when the subject was stimulated with the same motion profile (i.e., rotation of the gyroscope in the yaw plane) while sitting on a nonrotating, stable chair. Similar findings were also previously reported by Lewis et al. [2002] in an animal model.

Preservation of the (Residual) Hearing. The use of a VI requires implantation of an electrode in or in the vicinity of the vestibular system and its afferents. Two main surgical approaches have been developed: the intralabyrin-

Electrical Vestibular Stimulation in

Humans thine approach and the extralabyrinthine approach [Wall et al., 2007; Rubinstein et al., 2012]. The intralabyrinthine approach entails opening up the bony labyrinth so that the electrode can be inserted in the perilymphatic space [Bierer et al., 2012; Rubinstein et al., 2012; van de Berg et al., 2012]. Placing the vestibular electrode outside of the labyrinth and directly on the vestibular nerve or even on Scarpa's ganglion is called the extralabyrinthine approach [Wall et al., 2007; van de Berg et al., 2012]. Both approaches can lead to electrically evoked vestibular responses, but the risk of losing residual auditory and vestibular function is believed to be higher with the intralabyrinthine approach as it is likely that the endolymphatic compartment is penetrated during the insertion of the electrode in the perilymphatic space. As most of the abovementioned VI studies included patients with severe SNHL or deafness, preservation of residual hearing was not the primary research objective. In other study populations, hearing preservation during and after the vestibular implantation might be, however, of great importance. Approximately $31-78 \%$ of the BVP patients have been shown to have concurrent hearing loss, which means that 22 $69 \%$ of the BVP patients have normal hearing and would absolutely benefit from hearing preserving surgical techniques [Zingler et al., 2009; Lucieer et al., 2016; Dobbels et al., 2018].

A disadvantage of the extralabyrinthine approach is that it carries the risk of inducing both sensorineural and conductive hearing loss together with facial nerve damage. Nonetheless, the electrode is much closer to its target than it is with the intralabyrinthine approach. Therefore, a smaller amount of electrical currents might be needed with reduced current spread as a result [Feigl et al., 2009; van de Berg et al., 2012].

In some VI designs, intracochlear electrode arrays are available so that simultaneous vestibular and cochlear electrical stimulation can be provided, although no reports of the simultaneous activation have been reported yet. Patients with cochleovestibular disorders may benefit from this combined stimulation, but in patients with preoperatively residual and functional hearing, the need for the intracochlear electrode would only become apparent after the vestibular implantation if the hearing appears to be lost. This postoperative, iatrogenic hearing loss would imply additional surgery with consequent risks and costs.

Preservation and Influence of the Residual Vestibular Function. Currently, the patient population recruited for VI implantation mostly consists of patients with "complete" bilateral vestibular loss. However, most patients with such losses still have some residual ampullary and/ 
or otolith function. More specifically, the vestibular system has a sustained and transient response system which receive their input from a continuum of regular and irregular primary afferents. In some disorders or treatment options, the structures of one of these systems may be partially or even fully preserved (e.g., gentamicin mostly affects the transient system) [Curthoys et al., 2017]. If the natural stimulus fits into the physiological response profile of these intact afferents, a combined artificial and natural stimulation may result in an interaction between the evoked responses. Such phenomena have been previously reported by Golub et al. [2014] and van de Berg et al. [2017].

Additionally, structural damage induced by the implantation can result in fibrosis. In case of device failure, the fibrosis might prevent a reimplantation. Device failure is not unlikely to occur as vestibular patients are at increased risk of falling and this has also been born out in the setting of cochlear implantation [Herdman et al., 2000; Agrawal et al., 2009; Wolter et al., 2015].

Summarizing, it should be at least attempted to preserve the residual functions of the entire inner ear during vestibular (and cochlear) implantation, depending on the nature and the clinical profile of the vestibular patient's disorder.

\section{Galvanic Stimulation of the Transient Vestibular}

System

Recently, a renewed interest in GVS has also arisen from the need of treatment options for BVP patients. Although both the sustained and transient vestibular system are activated by the galvanic stimuli, it was previously shown that the irregular afferents have a significantly lower threshold for GVS than the regular afferents [Goldberg et al., 1984; Kim and Curthoys, 2004]. Different types of stimuli have been used for evoking otolith and SCC responses with GVS in both healthy subjects and in patients with vestibular dysfunctions: monophasic pulses (or direct current signals) [Krizkova and Hlavacka, 1994; Kim and Curthoys, 2004; MacDougall et al., 2005; Aw et al., 2006; Day et al., 2011; Kammermeier et al., 2017], stochastic stimuli or noise [Mulavara et al., 2011; Iwasaki et al., 2014; Goel et al., 2015; Mulavara et al., 2015; Fujimoto et al., 2016; Wuehr et al., 2016a, b; Wuehr et al., 2017; Iwasaki et al., 2018; Keywan et al., 2018; Serrador et al., 2018; Temple et al., 2018; Wuehr et al., 2018], sinusoidal waves [Coats, 1972; Petersen et al., 1994; Mackenzie and Reynolds, 2018] or multi-sine waves [MacDougall et al., 2006].

Currently, different research groups are investigating the stochastic stimuli (i.e., noise), as the (controversial) concept of stochastic resonance indicates that in a nonlinear system, like the vestibular system, low residual function may be amplified when an imperceptible noise is added [Mulavara et al., 2011; Iwasaki et al., 2014; Goel et al., 2015; Mulavara et al., 2015; Fujimoto et al., 2016; Wuehr et al., 2016a, b,2017; Iwasaki et al., 2018; Keywan et al., 2018; Serrador et al., 2018; Temple et al., 2018; Wuehr et al., 2018]. The trademark characteristic of stochastic resonance is a bell-shaped response curve to an increased noise strength; implying that noisy stimulation with too low or too high amplitudes will degrade the evoked response and that the amplitude range in between these upper and lower limits will result in improved outcomes [Moss et al., 2004; Mulavara et al., 2015]. Recently, Wuehr et al. [2018] confirmed this theory by adding a noisy galvanic stimulus to a sinusoidal galvanic stimulus. In $90 \%(22 / 24)$ of the healthy subjects, this addition led to a lowered threshold for evoking the vestibulospinal reflex. This effect was seen for stimulation amplitudes ranging from 0.3 to $1.1 \mathrm{~mA}$ but stimulation levels outside this range (i.e., below $0.3 \mathrm{~mA}$ or above $1.1 \mathrm{~mA}$ ) resulted in a decreased outcome. The response curve in this study was thus bell-shaped and supportive for the existence of a distinct response to stochastic resonance in the human vestibular system [Wuehr et al., 2018].

Furthermore, Serrador et al. [2018] showed that the addition of noise to a sinusoidal galvanic stimulus also increased the gain of the OCR in elderly patients, but not in young patients. Moreover, subjects with gains close to normal did not improve when noise was added to the sinusoidal signal. A ceiling effect was suggested based on these results. As the vestibular function is known to decrease with age, this study provided evidence for the beneficial effects of noisy GVS (nGVS) in patients with otolith-impaired function and possibly also of stochastic resonance in the human vestibular system.

The beneficial effects of nGVS are, however, not only present during acute stimulation. In several papers, a temporary, positive after-effect was reported, i.e., the improved balance functions remained for a couple of hours, even after the nGVS was ceased [Fujimoto et al., 2016]. Furthermore, it has been suggested that combining vestibular rehabilitation exercises with GVS can be beneficial for the overall outcome [Wuehr et al., 2017; Keywan et al., 2018; Serrador et al., 2018]. The feasibility of chronic motion modulation with GVS, however, has yet to be defined.

A huge difference compared to the unilaterally implanted SCC implant is that GVS can provide bilateral vestibular information simultaneously to the vestibular
18

Audiol Neurotol 2020;25:6-24 DOI: $10.1159 / 000502407$
Sluydts et al. 
receptors and afferents [Gensberger et al., 2016]. Therefore, baseline adaptation is not needed, which might be beneficial for the functional implementation of this approach. Furthermore, the reported adverse effects of GVS are limited and, in general, it is believed that GVS is a safe and well tolerable method [MacDougall et al., 2006; Wilkinson et al., 2009]. Although rare, skin lesions or pain may occur as the currents are being sent (repetitively) through the skin [Bos and Jongkees, 1963; Fitzpatrick et al., 1994]. Other examples of reported sensations were "prickly," "tickling," or "tapping" cutaneous sensations, head movement, and poststimulation nausea [Dakin et al., 2007; Ehtemam et al., 2012]. Furthermore, unintentional (sub)clinical cochlear or facial nerve stimulation should be further investigated, together with a more userfriendly application method of the electrical stimuli [Ueberfuhr et al., 2017].

\section{Discussion}

The overall trend in the abovementioned studies is that electrical stimuli can activate the vestibular system to a certain extent. Nonetheless, all three stimulation methods (vestibular co-stimulation, EVS with a VI, and GVS) are still under investigation and require further optimization in order to become functional applications.

A major issue that needs to be addressed in future research is which stimulation paradigm (type of modulation, stimulus waveform etc.) is the most appropriate for each of these stimulation methods. Concurrent firm- and software modifications will probably be required in order to provide the desired stimuli. Further, the concept of stochastic resonance in the vestibular system may play a role in the restoration of (or amplification of residual) vestibular function.

The electrode design is another aspect that will be subjected to further research, especially for the VI. As mentioned above, the preservation of residual auditory and vestibular function is one of the targets in both vestibular and cochlear implantation. This aspect will concur with the further optimization and exploration of the surgical techniques.

Another aspect of the VI designs is whether they should be single- or multichannel. So far, only the human MVI trial of the Johns Hopkins group showed results on simultaneously activating more than one SCC electrode with a torsional eye movement as a result [Boutros et al., 2018c; Della Santina, 2018a]. These results might indicate that more complex stimulation patterns may result in

Electrical Vestibular Stimulation in Humans more accurate response patterns. Whether a multichannel VI is needed to provide those more complex patterns is a question that remains to be answered. The abovementioned concepts of central vestibular convergence and multisensory integration may not need explicit multichannel input. Perhaps a simple electrical baseline provided by a single-channel VI will already suffice for activating and/or boosting the multisensory integration in a functional way?

Another aspect that also applies mainly to the VI is that the currently available VIs are based on the designs and techniques of CIs. Consequently, the stimulation possibilities are often restricted to those applied in CIs. Due to this analogy, some VI prototypes are limited to amplitude modulation. As mentioned above, both amplitude and frequency modulation have been shown to be capable of evoking vestibular responses. There is, however, no current consensus regarding which stimulation paradigm is more effective. In recent animal and computer models, a third stimulation paradigm (i.e., co-modulation) has been introduced and might provide new opportunities for vestibular stimulation.

Analogous to the CI, postoperative fitting sessions have been suggested in order to reduce adverse effects and/or to improve vestibular outcomes [Fridman et al., 2010]. Although having a good backup system for improving the vestibular outcomes at the individual patient level is needed, it should be attempted to optimize the artificial treatment option (i.e., vestibular co-stimulation, EVS with a VI, or GVS) before its commercialization.

An additional aspect that probably will be investigated in the future is the effect of combining EVS or GVS with vestibular rehabilitation and/or sensory substitution systems. It seems that multisensory integration prior to any artificial vestibular stimulation is not strong enough to compensate for the impaired vestibular function. Providing artificial stimuli to the vestibular system seems to activate or boost the multisensory integration so that improvement is seen in different vestibular responses. As vestibular rehabilitation and the use of sensory substitution systems can contribute to this central process of multisensory integration, the combination of these treatment options might be worth further exploration.

When the results of the BalanCI and the GVS studies are considered, the question is raised whether a VI is even needed. However, the different clinical profiles of the patients (with and without residual auditory and/or residual vestibular function) indicate that different approaches are warranted. Furthermore, the difference between children and adults with CIs should be incorporated in these 
studies. The data of the BalanCI study was obtained in children, whereas all VI and GVS studies were conducted in adult study populations. Neural plasticity is known to be higher in children than in adults, so perhaps children receiving a $\mathrm{CI}$ have already enough information when a simple baseline electrical stimulus, that may or may not be head-referenced, is provided through the intracochlear array.

\section{Conclusion}

The focus of several vestibular research groups is currently on the development of an effective and efficient therapy for artificially restoring the vestibular function in vestibular patients.

Electrical stimulation can be divided into three subtypes: vestibular co-stimulation with a CI, direct vestibular stimulation with a VI, and GVS through surface electrodes. Although the currently available results of all three approaches seem promising, it has yet to be defined which option is more desirable based on applicability and efficiency. It is indeed possible and even likely that there is a place for all three approaches, given the diversity of the patient population who serves to gain from such technologies.

\section{Acknowledgement}

The authors would like to acknowledge the contribution of Dr. Raymond van de Berg and Professor Floris Wuyts. Both have reviewed (parts of) the manuscript.

\section{Statement of Ethics}

The authors have no ethical conflicts to disclose.

\section{Disclosure Statement}

Speaker's Bureau Interacoustics (S.L.C.), Cochlear Corporation (S.L.C., B.C.P.), Royalties Plural Publishing Editor: Balance Disorders in the Pediatric Population (S.L.C.), Patent Holder: Patents No. 7041-0: Systems dnd Methods for Balance Stabilization (S.L.C., B.C.P.), Sponsored Research Agreement Cochlear Americas (S.L.C., B.C.P.). I.C. is an unpaid consultant to GN Otometrics, Taastrup, Denmark, but has received support from GN Otometrics for travel and attendance at conferences and workshops.

\section{Funding Sources}

Horizon 2020 project H2020-Fetopen-2016-2017 (BionicVEST).

\section{Author Contributions}

All authors have provided substantial contributions to the conception or design of the work or the interpretation of data for the work (M.S., I.C., R.V., B.C.P., S.L.C., A.R.M., A.R., S.B.B., M.B., M.M., A.Z.). All of them worked on the draft or revised it critically for important intellectual content (M.S., I.C., R.V., B.C.P., S.L.C., A.R.M., A.R., S.B., M.B., A.Z.). The final version was approved for publishing by all authors (M.S., I.C., R.V., B.C.P., S.L.C., A.R.M., A.R., S.B.B., M.B., M.M., A.Z.). The authors agree on accountability for all aspects of the work in ensuring that questions related to the accuracy or integrity of any part of the work are appropriately investigated and resolved (M.S., I.C., R.V., B.C.P., S.L.C., A.R.M., A.R., S.B.B., M.B., M.M., A.Z.).

\section{References}

Agrawal Y, Carey JP, Della Santina CC, Schubert MC, Minor LB. Disorders of balance and vestibular function in US adults: data from the National Health and Nutrition Examination Survey, 2001-2004. Arch Intern Med. 2009 May;169(10):938-44.

Aw ST, Todd MJ, Halmagyi GM. Latency and initiation of the human vestibuloocular reflex to pulsed galvanic stimulation. J Neurophysiol. 2006 Aug;96(2):925-30.

Bance ML, O'Driscoll M, Giles E, Ramsden RT. Vestibular stimulation by multichannel cochlear implants. Laryngoscope. 1998 Feb; 108(2):291-4

Basta D, Todt I, Eisenschenk A, Ernst A. Vestibular evoked myogenic potentials induced by intraoperative electrical stimulation of the human inferior vestibular nerve. Hear Res. 2005 Jun;204(1-2):111-4.
Basta D, Todt I, Goepel F, Ernst A. Loss of saccular function after cochlear implantation: the diagnostic impact of intracochlear electrically elicited vestibular evoked myogenic potentials. Audiol Neurotol. 2008;13(3):187-92.

Berrettini S, Vito A, Bruschini L, Passetti S, Forli F. Facial nerve stimulation after cochlear implantation: our experience. Acta Otorhinolaryngol Ital. $2011 \mathrm{Feb}$;31(1):11-6.

Bierer SM, Ling L, Nie K, Fuchs AF, Kaneko CR, Oxford T, et al. Auditory outcomes following implantation and electrical stimulation of the semicircular canals. Hear Res. 2012 May; 287(1-2):51-6.

Bigelow DC, Kay DJ, Rafter KO, Montes M, Knox GW, Yousem DM. Facial nerve stimulation from cochlear implants. Am J Otol. 1998 Mar; 19(2):163-9.
Bos JH, Jongkees LB. On galvanic stimulation of the labyrinth. Pract Otorhinolaryngol (Basel). 1963;25:345-8.

Boutros P, Schoo D, Rahman M, Valentin N, Chow M, Gimmon Y, et al. Multichannel Vestibular Implant: Continuous Restoration of the $\mathrm{Hu}$ man Vestibulo-Ocular Reflex. XXXth Bárány Society Meeting; 2018a; Uppsala, Sweden.

Boutros P. Multichannel Vestibular Implant: Continuous Restoration of the Human Vestibulo-Ocular Reflex. Presentation presented at XXXth Bárány Society Meeting; 2018b; Uppsala, Sweden.

Boutros PJ, Schoo D, Rahman M, Valentin NS, Chow M, Gimmon Y, et al. First-in-human safety and preliminary efficacy results for the MVI Multichannel Vestibular Implant. XXXth Bárány Society Meeting; 2018c; Uppsala, Sweden. 
Brontë-Stewart HM, Lisberger SG. Physiological properties of vestibular primary afferents that mediate motor learning and normal performance of the vestibulo-ocular reflex in monkeys. J Neurosci. 1994 Mar;14(3 3 Pt 1):1290308.

Brown KE, Whitney SL, Wrisley DM, Furman JM. Physical therapy outcomes for persons with bilateral vestibular loss. Laryngoscope. 2001 Oct;111(10):1812-7.

Buchman CA, Joy J, Hodges A, Telischi FF, Balkany TJ. Vestibular effects of cochlear implantation. Laryngoscope. 2004 Oct; $114(10 \mathrm{Pt}$ 2 Suppl 103):1-22.

Chow M, Gimmon Y, Schoo D, Trevino C, Boutros PJ, Rahman M, et al. Multichannel Vestibular Implant Early Feasibility Study: Gait and Posture Outcomes. XXXth Bárány Society Meeting; 2018a; Uppsala, Sweden.

Chow M, Hageman KN, Roberts D, Della Santina CC. Temporal Dynamics of Eye Movements Elicited by Combined Otolith and Semicircular Canal Stimulation. XXXth Bárány Society Meeting; 2018b; Uppsala, Sweden.

Chow M. Multichannel Vestibular Implant Early Feasibility Study: Gait and Posture Outcomes. Presentation presented at XXXth Bárány Society Meeting; 2018a; Uppsala, Sweden.

Chow M. Spatial Selectivity of Eye Movements Elicited by Combined Otolith and Semicircular Canal Stimulation. Presentation presented at XXXth Bárány Society Meeting; 2018b; Uppsala, Sweden.

Chow M. Temporal Dynamics of Eye Movements Elicited by Combined Otolith and Semicircular Canal Stimulation. Presentation presented at XXXth Bárány Society Meeting; 2018c; Uppsala, Sweden.

Coats AC. The sinusoidal galvanic body-sway response. Acta Otolaryngol. 1972 Sep;74(3): $155-62$.

Cohen B, Suzuki JI. Eye movements induced by ampullary nerve stimulation. Am J Physiol. 1963 Feb;204:347-51.

Coordes A, Basta D, Götze R, Scholz S, Seidl RO, Ernst A, et al. Sound-induced vertigo after cochlear implantation. Otol Neurotol. 2012 Apr;33(3):335-42.

Curthoys IS, MacDougall HG, Vidal PP, de Waele C. Sustained and transient vestibular systems: A physiological basis for interpreting vestibular function. Front Neurol. 2017 Mar;8:117.

Curthoys IS, Markham CH. Convergence of labyrinthine influences on units in the vestibular nuclei of the cat. I. Natural stimulation. Brain Res. 1971 Dec;35(2):469-90.

Cushing SL, Chia R, James AL, Papsin BC, Gordon KA. A test of static and dynamic balance function in children with cochlear implants: the vestibular olympics. Arch Otolaryngol Head Neck Surg. 2008 Jan;134(1):34-8.

Cushing SL, Papsin BC, Gordon KA. Incidence and characteristics of facial nerve stimulation in children with cochlear implants. Laryngoscope. 2006 Oct;116(10):1787-91.
Cushing SL, Pothier D, Hughes C, Hubbard BJ, Gordon KA, Papsin BC. Providing auditory cues to improve stability in children who are deaf. Laryngoscope. 2012 Dec;122(S4 Suppl 4):S101-2.

Cushing SL, Wolter N, Gordon K, Campos J, Vilchez Madrigal L, Pothier D, et al. BalanCI: Improving balance in children with bilateral cochleovestibular loss using cochlear implants. XXXth Bárány Society Meeting; 2018a; Uppsala, Sweden.

Cushing SL. Vestibular and Balance Function is Impaired in Children with Unilateral Sensorineural Hearing Loss. Presentation presented at XXXth Bárány Society Meeting; 2018b; Uppsala, Sweden.

Dai C, Fridman GY, Chiang B, Rahman MA, Ahn JH, Davidovics NS, et al. Directional plasticity rapidly improves $3 \mathrm{D}$ vestibulo-ocular reflex alignment in monkeys using a multichannel vestibular prosthesis. J Assoc Res Otolaryngol. 2013 Dec;14(6):863-77.

Dakin CJ, Son GM, Inglis JT, Blouin JS. Frequency response of human vestibular reflexes characterized by stochastic stimuli. J Physiol. 2007 Sep;583(Pt 3):1117-27.

Davidovics NS, Fridman GY, Della Santina CC Co-modulation of stimulus rate and current from elevated baselines expands head motion encoding range of the vestibular prosthesis. Exp Brain Res. 2012 May;218(3):389-400.

Day BL, Ramsay E, Welgampola MS, Fitzpatrick RC. The human semicircular canal model of galvanic vestibular stimulation. Exp Brain Res. 2011 May;210(3-4):561-8.

Della Santina CC, Migliaccio AA, Hayden R, Melvin TA, Fridman GY, Chiang B, et al. Current and future management of bilateral loss of vestibular sensation - an update on the Johns Hopkins Multichannel Vestibular Prosthesis Project. Cochlear Implants Int. 2010 Sep; 11(sup2 Suppl 2):2-11.

Della Santina CC. First-in-human Safety and Preliminary Efficacy Results for the MVI ${ }^{\mathrm{TM}}$ Multichannel Vestibular Implant. Presentation presented at XXXth Bárány Society Meeting; 2018a; Uppsala, Sweden.

Della Santina CC. First-in-human safety and preliminary efficacy results for the MVI Multichannel Vestibular Implant. Presentation presented at CI2018; 2018b; Antwerp, Belgium.

DiGiovanna J, Nguyen TA, Guinand N, PérezFornos A, Micera S. Neural Network Model of Vestibular Nuclei Reaction to Onset of Vestibular Prosthetic Stimulation. Front Bioeng Biotechnol. 2016 Apr;4:34.

Dobbels B, Peetermans O, Boon B, De Belder J, Matthysen S, Van de Heyning P, et al. Etiology and hearing status of 129 patients with bilateral vestibulopathy. XXXth Bárány Society Meeting; 2018; Uppsala, Sweden.

Ehtemam F, Forbes PA, Schouten AC, van der Helm FC, Happee R. Galvanic vestibular stimulation elicits consistent head-neck motion in seated subjects. IEEE Trans Biomed Eng. 2012 Jul;59(7):1978-84.
Eisenberg LS, Nelson JR, House WF. Effects of the single-electrode cochlear implant on the vestibular system of the profoundly deaf adult. Ann Otol Rhinol Laryngol Suppl. 1982 MarApr;91 2 Pt 3:47-54.

Feigl GC, Fasel JH, Anderhuber F, Ulz H, Rienmüller R, Guyot JP, et al. Superior vestibular neurectomy: a novel transmeatal approach for a denervation of the superior and lateral semicircular canals. Otol Neurotol. 2009 Aug. 30(5):586-91.

Fernandez C, Goldberg JM. Physiology of peripheral neurons innervating semicircular canals of the squirrel monkey. II. Response to sinusoidal stimulation and dynamics of peripheral vestibular system. J Neurophysiol. 1971 Jul;34(4):661-75.

Fitzpatrick R, Burke D, Gandevia SC. Task-dependent reflex responses and movement illusions evoked by galvanic vestibular stimulation in standing humans. J Physiol. 1994 Jul; 478(Pt 2):363-72.

Fridman GY, Davidovics NS, Dai C, Migliaccio AA, Della Santina CC. Vestibulo-ocular reflex responses to a multichannel vestibular prosthesis incorporating a 3D coordinate transformation for correction of misalignment. J Assoc Res Otolaryngol. 2010 Sep;11(3):36781.

Fujimoto C, Yamamoto Y, Kamogashira T, Kinoshita M, Egami N, Uemura Y, et al. Noisy galvanic vestibular stimulation induces a sustained improvement in body balance in elderly adults. Sci Rep. 2016 Nov;6(1):37575.

Gensberger KD, Kaufmann AK, Dietrich H, Branoner F, Banchi R, Chagnaud BP, et al. Galvanic Vestibular Stimulation: Cellular Substrates and Response Patterns of Neurons in the Vestibulo-Ocular Network. J Neurosci. 2016 Aug;36(35):9097-110.

Gnanasegaram JJ, Parkes WJ, Cushing SL, McKnight CL, Papsin BC, Gordon KA. Stimulation from Cochlear Implant Electrodes Assists with Recovery from Asymmetric Perceptual Tilt: Evidence from the Subjective Visual Vertical Test. Front Integr Nuerosci. 2016 Sep;10:32.

Goel R, Kofman I, Jeevarajan J, De Dios Y, Cohen HS, Bloomberg JJ, et al. Using Low Levels of Stochastic Vestibular Stimulation to Improve Balance Function. PLoS One. 2015 Aug; 10(8):e0136335.

Goldberg JM, Smith CE, Fernández C. Relation between discharge regularity and responses to externally applied galvanic currents in vestibular nerve afferents of the squirrel monkey. J Neurophysiol. 1984 Jun;51(6):1236-56.

Golub JS, Ling L, Nie K, Nowack A, Shepherd SJ, Bierer SM, et al. Prosthetic implantation of the human vestibular system. Otol Neurotol. 2014 Jan;35(1):136-47.

Gong W, Merfeld DM. System design and performance of a unilateral horizontal semicircular canal prosthesis. IEEE Trans Biomed Eng. 2002 Feb;49(2):175-81. 
Goto F, Meng H, Bai R, Sato H, Imagawa M, Sasaki $\mathrm{M}$, et al. Eye movements evoked by selective saccular nerve stimulation in cats. Auris Nasus Larynx. 2004 Sep;31(3):220-5.

Goto F, Meng H, Bai R, Sato H, Imagawa M, Sasaki M, et al. Eye movements evoked by the selective stimulation of the utricular nerve in cats. Auris Nasus Larynx. 2003 Dec;30(4): 341-8.

Guinand N, Guyot JP, Kingma H, Kos I, Pelizzone M. Vestibular Implants: The First Steps in Humans.Conf Proc IEEE Eng Med Biol Soc 2011;2262-4.

Guinand N, Van de Berg R, Cavuscens S, Ranieri M, Schneider E, Lucieer F, et al. The Video Head Impulse Test to Assess the Efficacy of Vestibular Implants in Humans. Front Neurol. 2017 Nov;8:600.

Guinand N, Van de Berg R, Cavuscens S, Stokroos R, Ranieri M, Pelizzone M, et al. Restoring Visual Acuity in Dynamic Conditions with a Vestibular Implant. Front Neurosci. 2016 Dec;10:577.

Guinand N, van de Berg R, Cavuscens S, Stokroos RJ, Ranieri M, Pelizzone M, et al. Vestibular Implants: 8 Years of Experience with Electrical Stimulation of the Vestibular Nerve in 11 Patients with Bilateral Vestibular Loss. ORL J Otorhinolaryngol Relat Spec. 2015a;77(4): $227-40$.

Guinand N, van de Berg R, Ranieri M, Cavuscens S, DiGiovanna J, Nguyen TA, et al. Vestibular implants: hope for improving the quality of life of patients with bilateral vestibular loss. Conf Proc IEEE Eng Med Biol Soc. 2015b; 2015:7192-5

Guyot JP, Perez Fornos A, Guinand N, van de Berg R, Stokroos R, Kingma H. Vestibular assistance systems: promises and challenges. J Neurol. 2016 Apr;263(1 Suppl 1):S30-5.

Guyot JP, Sigrist A, Pelizzone M, Feigl GC, Kos MI. Eye Movements in Response to Electric Stimulation of the Lateral and Superior Ampullary Nerves. Ann Otol Rhinol Laryngol. 2011a Feb;120(2):81-7.

Guyot JP, Sigrist A, Pelizzone M, Kos MI. Adaptation to Steady-State Electrical Stimulation of the Vestibular System in Humans. Ann Otol Rhinol Laryngol. 2011b Mar;120(3):143-9.

Hageman KN, Chow MR, Boutros PJ, Roberts D, Tooker AC, Lee KY, et al. Design of a Vestibular Prosthesis for Sensation of Gravitoinertial Acceleration. J Med Device. 2016 Sep; 10(3):030923.

Hageman KN, Chow MR, Roberts D, Della Santina CC. Spatial Selectivity of Eye Movements Elicited by Combined Otolith and Semicircular Canal Stimulation. XXXth Bárány Society Meeting; 2018; Uppsala, Sweden.

Hain TC, Helminski JO. Anatomy and physiology of the normal vestibular system. In: Herdman SJ, editor. Vestibular Rehabilitation. 3rd ed. Philadelphia (PA): F. A. Davis Company; 2007. pp. 2-18.
Hall CD, Schubert MC, Herdman SJ. Prediction of fall risk reduction as measured by dynamic gait index in individuals with unilateral vestibular hypofunction. Otol Neurotol. 2004 Sep;25(5):746-51.

Hallemans A, Mertens G, Van de Heyning P, Van Rompaey V. Playing Music May Improve the Gait Pattern in Patients with Bilateral Caloric Areflexia Wearing a Cochlear Implant: Results from a Pilot Study. Front Neurol. 2017 Aug;8:404.

Halmagyi GM, Curthoys IS. Otolith function test. In: Herdman SJ, editor. Vestibular Rehabilitation. 3rd ed. Philadelphia (PA): F.A. Davis Company; 2007. pp. 144-61.

Herdman SJ, Blatt P, Schubert MC, Tusa RJ. Falls in patients with vestibular deficits. Am J Otol. 2000 Nov;21(6):847-51.

Herdman SJ, Clendaniel RA. Assessment and interventions for the patient with complete vestibular loss. In: Herdman SJ, editor. Vestibular Rehabilitation. 3rd ed. Philadelphia (PA): F. A. DavisCompany; 2007. pp. 338-59.

Herdman SJ, Hall CD, Maloney B, Knight S, Ebert $\mathrm{M}$, Lowe J. Variables associated with outcome in patients with bilateral vestibular hypofunction: preliminary study. J Vestib Res. 2015; 25(3-4):185-94.

Herdman SJ, Schubert MC, Das VE, Tusa RJ. Recovery of dynamic visual acuity in unilateral vestibular hypofunction. Arch Otolaryngol Head Neck Surg. 2003 Aug;129(8):819-24.

Hlavacka F, Njiokiktjien C. Postural responses evoked by sinusoidal galvanic stimulation of the labyrinth. Influence of head position. Acta Otolaryngol. 1985 Jan-Feb;99(1-2):107-12.

Ito J. Influence of the multichannel cochlear implant on vestibular function. Otolaryngol Head Neck Surg. 1998 Jun;118(6):900-2.

Iwasaki S, Fujimoto C, Egami N, Kinoshita M, Togo F, Yamamoto Y, et al. Noisy vestibular stimulation increases gait speed in normals and in bilateral vestibulopathy. Brain Stimul. 2018 Jul-Aug;11(4):709-15.

Iwasaki S, Yamamoto Y, Togo F, Kinoshita M, Yoshifuji Y, Fujimoto C, et al. Noisy vestibular stimulation improves body balance in bilateral vestibulopathy. Neurology. 2014 Mar; 82(11):969-75.

Jacobson GP, Calder JH. Self-perceived balance disability/handicap in the presence of bilateral peripheral vestibular system impairment. J Am Acad Audiol. 2000 Feb;11(2):76-83.

Janssen M, Pas R, Aarts J, Janssen-Potten Y, Vles $\mathrm{H}$, Nabuurs C, et al. Clinical observational gait analysis to evaluate improvement of balance during gait with vibrotactile biofeedback. Physiother Res Int. 2012 Mar;17(1):411.

Jin Y, Shinjo Y, Akamatsu Y, Ogata E, Nakamura M, Kianoush S, et al. Vestibular evoked myogenic potentials evoked by multichannel cochlear implant - influence of C levels. Acta Otolaryngol. 2008 Mar;128(3):284-90.
Kammermeier S, Singh A, Bötzel K. Intermediate Latency-Evoked Potentials of Multimodal Cortical Vestibular Areas: galvanic Stimulation. Front Neurol. 2017 Nov;8:587.

Kelsall DC, Shallop JK, Brammeier TG, Prenger EC. Facial nerve stimulation after Nucleus 22-channel cochlear implantation. Am J Otol. 1997 May; 18(3):336-41.

Keywan A, Wuehr M, Pradhan C, Jahn K. Noisy galvanic stimulation improves roll-tilt vestibular perception in healthy subjects. Front Neurol. 2018 Mar;9:83.

Kim J, Curthoys IS. Responses of primary vestibular neurons to galvanic vestibular stimulation (GVS) in the anaesthetised guinea pig. Brain Res Bull. 2004 Sep;64(3):265-71.

Krebs DE, Gill-Body KM, Riley PO, Parker SW Double-blind, placebo-controlled trial of rehabilitation for bilateral vestibular hypofunction: preliminary report. Otolaryngol Head Neck Surg. 1993 Oct;109(4):735-41.

Krizková M, Hlavacka F. Binaural monopolar galvanic vestibular stimulation reduces body sway during human stance. Physiol Res. 1994; 43(3):187-92.

Kushiro K, Zakir M, Sato H, Ono S, Ogawa Y, Meng H, et al. Saccular and utricular inputs to single vestibular neurons in cats. Exp Brain Res. 2000 Apr;131(4):406-15.

Latt LD, Sparto PJ, Furman JM, Redfern MS. The steady-state postural response to continuous sinusoidal galvanic vestibular stimulation. Gait Posture. 2003 Oct;18(2):64-72.

le Nobel GJ, Hwang E, Wu A, Cushing S, Lin VY. Vestibular function following unilateral cochlear implantation for profound sensorineural hearing loss. J Otolaryngol Head Neck Surg. 2016 Jun;45(1):38.

Lewis RF, Gong W, Ramsey M, Minor L, Boyle R, Merfeld DM. Vestibular adaptation studied with a prosthetic semicircular canal. J Vestib Res. 2002-2003;12(2-3):87-94.

Lewis RF, Haburcakova C, Gong W, Makary C, Merfeld DM. Vestibuloocular reflex adaptation investigated with chronic motion-modulated electrical stimulation of semicircular canal afferents. J Neurophysiol. 2010 Feb; 103(2):1066-79.

Lewis RF. Vestibular implants studied in animal models: clinical and scientific implications. J Neurophysiol. 2016 Dec;116(6):2777-88.

Lucieer F, Vonk P, Guinand N, Stokroos R, Kingma H, van de Berg R. Bilateral Vestibular Hypofunction: Insights in Etiologies, Clinical Subtypes, and Diagnostics. Front Neurol. 2016 Mar;7:26.

MacDougall HG, Brizuela AE, Burgess AM, Curthoys IS, Halmagyi GM. Patient and normal three-dimensional eye-movement responses to maintained (DC) surface galvanic vestibular stimulation. Otol Neurotol. 2005 May; 26(3):500-11.

MacDougall HG, Moore ST, Curthoys IS, Black FO. Modeling postural instability with Galvanic vestibular stimulation. Exp Brain Res. 2006 Jun;172(2):208-20. 
Mackenzie SW, Reynolds RF. Ocular torsion responses to sinusoidal electrical vestibular stimulation. J Neurosci Methods. 2018 Jan; 294:116-21.

Markham CH, Curthoys IS. Convergence of labyrinthine influences on units in the vestibular nuclei of the cat. II. Electrical stimulation. Brain Res. 1972 Aug;43(2):383-96.

Mazaheryazdi M, Moossavi A, Sarrafzadah J, Talebian S, Jalaie S. Study of the effects of hearing on static and dynamic postural function in children using cochlear implants. Int J Pediatr Otorhinolaryngol. 2017 Sep;100:1822.

McCrum C, Willems P, van de Berg R, Cavuscens S, Guinand N, Guyot JP, et al. Preliminary observations of the acute effects of vestibular nerve stimulation on stride length and time in two patients with bilateral vestibular hypofunction. Gait Posture. 2016 Oct;49S:124.

Minor LB, Goldberg JM. Vestibular-nerve inputs to the vestibulo-ocular reflex: a functionalablation study in the squirrel monkey. J Neurosci. 1991 Jun;11(6):1636-48.

Miwa T, Minoda R, Matsuyoshi $\mathrm{H}$, Takeda H. The effect of cochlear implants on vestibularevoked myogenic potential responses and postural stability. Auris Nasus Larynx. 2019 Feb;46(1):50-7.

Moss F, Ward LM, Sannita WG. Stochastic resonance and sensory information processing: a tutorial and review of application. Clin Neurophysiol. $2004 \mathrm{Feb} ; 115(2): 267-81$.

Mulavara AP, Fiedler MJ, Kofman IS, Wood SJ, Serrador JM, Peters B, et al. Improving balance function using vestibular stochastic resonance: optimizing stimulus characteristics. Exp Brain Res. 2011 Apr;210(2):303-12.

Mulavara AP, Kofman IS, De Dios YE, Miller C, Peters BT, Goel R, et al. Using low levels of stochastic vestibular stimulation to improve locomotor stability. Front Syst Neurosci. 2015 Aug;9:117.

Nassif N, Balzanelli C, Redaelli de Zinis LO. Preliminary results of video Head Impulse Testing (vHIT) in children with cochlear implants. Int J Pediatr Otorhinolaryngol. 2016 Sep;88:30-3.

Nguyen TA, Cavuscens S, Ranieri M, Schwarz K, Guinand N, van de Berg R, et al. Characterization of Cochlear, Vestibular and CochlearVestibular Electrically Evoked Compound Action Potentials in Patients with a Vestibulo-Cochlear Implant. Front Neurosci. 2017 Nov; $11: 645$

Nguyen TA, DiGiovanna J, Cavuscens S, Ranieri M, Guinand N, van de Berg R, et al. Characterization of pulse amplitude and pulse rate modulation for a human vestibular implant during acute electrical stimulation. J Neural Eng. 2016 Aug;13(4):046023.

Nguyen TA, Ranieri M, DiGiovanna J, Peter O, Genovese V, Perez Fornos A, et al. A real-time research platform to study vestibular implants with gyroscopic inputs in vestibular deficient subjects. IEEE Trans Biomed Circuits Syst. 2014 Aug;8(4):474-84.
Nie K, Bierer SM, Ling L, Oxford T, Rubinstein JT, Phillips JO. Characterization of the electrically evoked compound action potential of the vestibular nerve. Otol Neurotol. 2011 Jan; 32(1):88-97.

Nie K, Ling L, Bierer SM, Kaneko CR, Fuchs AF, Oxford T, et al. An experimental vestibular neural prosthesis: design and preliminary results with rhesus monkeys stimulated with modulated pulses. IEEE Trans Biomed Eng. 2013 Jun;60(6):1685-92.

Papsin BC. Cochlear implantation in children with anomalous cochleovestibular anatomy. Laryngoscope. 2005 Jan;115(1 Pt 2 Suppl 106): $1-26$.

Parkes WJ, Gnanasegaram JJ, Cushing SL, McKnight CL, Papsin BC, Gordon KA. Vestibular evoked myogenic potential testing as an objective measure of vestibular stimulation with cochlear implants. Laryngoscope. 2017 Feb;127(2):E75-81.

Pelizzone M, Fornos AP, Guinand N, van de Berg R, Kos I, Stokroos R, et al. First functional rehabilitation via vestibular implants. Cochlear Implants Int. 2014 May; 15(sup1 Suppl 1):S62-4.

Perez Fornos A, Cavuscens S, Ranieri M, van de Berg R, Stokroos R, Kingma H, et al. The vestibular implant: A probe in orbit around the human balance system. J Vestib Res. 2017; 27(1):51-61.

Perez Fornos A, Guinand N, van de Berg R, Stokroos R, Micera S, Kingma H, et al. Artificial balance: restoration of the vestibulo-ocular reflex in humans with a prototype vestibular neuroprosthesis. Front Neurol. 2014 Apr;5: 66.

Petersen H, Magnusson M, Fransson PA, Johansson R. Vestibular disturbance at frequencies above $1 \mathrm{~Hz}$ affects human postural control. Acta Otolaryngol. 1994 May;114(3):225-30.

Petersen H, Magnusson M, Johansson R, Akesson $\mathrm{M}$, Fransson PA. Acoustic cues and postural control. Scand J Rehabil Med. 1995 Jun;27(2): 99-104.

Phillips C, Defrancisci C, Ling L, Nie K, Nowack A, Phillips JO, et al. Postural responses to electrical stimulation of the vestibular end organs in human subjects. Exp Brain Res. 2013 Aug; 229(2):181-95.

Phillips JO, Ling L, Nie K, Jameyson E, Phillips $\mathrm{CM}$, Nowack AL, et al. Vestibular implantation and longitudinal electrical stimulation of the semicircular canal afferents in human subjects. J Neurophysiol. 2015 Jun;113(10): 3866-92.

Phillips JO, Ling L, Nowack AL, Phillips CM, Nie $\mathrm{K}$, Rubinstein JT. The Dynamics of Prosthetically Elicited Vestibulo-Ocular Reflex Function Across Frequency and Context in the Rhesus Monkey. Front Neurosci. 2018 May; 12:88.

Polak M, Ulubil SA, Hodges AV, Balkany TJ. Revision cochlear implantation for facial nerve stimulation in otosclerosis. Arch Otolaryngol Head Neck Surg. 2006 Apr;132(4):398-404.
Precht W, Shimazu H, Markham CH. A mechanism of central compensation of vestibular function following hemilabyrinthectomy. J Neurophysiol. 1966 Nov;29(6):996-1010.

Psillas G, Pavlidou A, Lefkidis N, Vital I, Markou $\mathrm{K}$, Triaridis S, et al. Vestibular evoked myogenic potentials in children after cochlear implantation. Auris Nasus Larynx. 2014 Oct; 41(5):432-5.

Ramos de Miguel A, Falcon Gonzalez JC, Ramos Macias A. Vestibular Response to Electrical Stimulation of the Otolith Organs. Implications in the Development of A Vestibular Implant for the Improvement of the Sensation of Gravitoinertial Accelerations. J Int Adv Otol. 2017 Aug;13(2):154-61

Robinson AJ. Basic concepts in electricity and contemporary terminology electrotherapy. In: Robinson AJ, Snyder-Mackler L, editors. Clinical Electrophysiology: Electrotherapy and electrophysiological testing. 3rd ed. Philadelphia (PA): Lippincott Williams \& Wilkins; 2008. pp. 1-26.

Rubinstein D, Sandberg EJ, Cajade-Law AG. Anatomy of the facial and vestibulocochlear nerves in the internal auditory canal. AJNR Am J Neuroradiol. 1996 Jun-Jul;17(6):1099-105.

Rubinstein JT, Bierer S, Kaneko C, Ling L, Nie K, Oxford $\mathrm{T}$, et al. Implantation of the semicircular canals with preservation of hearing and rotational sensitivity: a vestibular neurostimulator suitable for clinical research. Otol Neurotol. 2012 Jul;33(5):789-96.

Rubinstein JT, Nie K, Bierer S, Ling L, Phillips JO. Signal processing for a vestibular neurostimulator. Conf Proc IEEE Eng Med Biol Soc. 2010;2010:6247.

Schils SJ. Review of electrotherapy devices for use in veterinary medicine. AAEP Proceedings. 2009;55:68-73.

Schneider E, Glasauer S, Dieterich M. Comparison of human ocular torsion patterns during natural and galvanic vestibular stimulation. J Neurophysiol. 2002 Apr;87(4):2064-73.

Schoo D, Boutros P, Chow M, Gimmon Y, Bowditch S, Rahman M, et al. Multichannel Vestibular Implant Early Feasibility Study: Safety and Audiometric Outcomes. XXXth Bárány Society Meeting; 2018; Uppsala, Sweden.

Schoo D. Multichannel Vestibular Implant Early Feasibility Study: Safety and Audiometric Outcomes. Presentation presented at XXXth Bárány Society Meeting; 2018; Uppsala, Sweden.

Serrador JM, Deegan BM, Geraghty MC, Wood SJ. Enhancing vestibular function in the elderly with imperceptible electrical stimulation. Sci Rep. 2018 Jan;8(1):336.

Shayman CS, Earhart GM, Hullar TE. Improvements in Gait With Hearing Aids and Cochlear Implants. Otol Neurotol. 2017 Apr;38(4): 484-6.

Smullen JL, Polak M, Hodges AV, Payne SB, King JE 3rd, Telischi FF, et al. Facial nerve stimulation after cochlear implantation. Laryngoscope. 2005 Jun;115(6):977-82. 
Strupp M, Kim JS, Murofushi T, Straumann D, Jen JC, Rosengren SM, et al. Bilateral vestibulopathy: Diagnostic criteria Consensus document of the Classification Committee of the Bárány Society. J Vestib Res. 2017;27(4):17789.

Suarez H, Angeli S, Suarez A, Rosales B, Carrera $\mathrm{X}$, Alonso R. Balance sensory organization in children with profound hearing loss and cochlear implants. Int J Pediatr Otorhinolaryngol. 2007 Apr;71(4):629-37.

Suzuki JI, Cohen B, Bender MB. Compensatory eye movements induced by vertical semicircular canalstimulation. Exp Neurol. 1964 Feb; 9(2):137-60.

Suzuki JI, Goto K, Komatsuzaki A, Nozue M. Otolithic influences on tonus changes of the extraocular muscles. A study on positional eye deviation and nystagmus. Ann Otol Rhinol Laryngol. 1968 Oct;77(5):959-70.

Suzuki JI, Goto K, Tokumasu K, Cohen B. Implantation of electrodes near individual vestibular nerve branches in mammals. Ann Otol Rhinol Laryngol. 1969a Aug;78(4):815-26.

Suzuki JI, Tokumasu K, Goto K. Eye movements from single utricular nerve stimulation in the cat. Acta Otolaryngol. 1969b Oct;68(4):35062.

Temple DR, De Dios YE, Layne CS, Bloomberg JJ, Mulavara AP. Efficacy of Stochastic Vestibular Stimulation to Improve Locomotor Performance During Adaptation to Visuomotor and Somatosensory Distortion. Front Physiol. 2018 Mar;9:301.

Tokumasu K, Suzuki JI, Goto K. A study of the current spread on electric stimulation of the individual utricular and ampullary nerves. Acta Otolaryngol. 1971 Apr;71(4):313-8.

Uchino Y, Kushiro K. Differences between otolith- and semicircular canal-activated neural circuitry in the vestibular system. Neurosci Res. 2011 Dec;71(4):315-27.
Uchino Y, Sasaki M, Sato H, Bai R, Kawamoto E. Otolith and canal integration on single vestibular neurons in cats. Exp Brain Res. 2005 Jul;164(3):271-85.

Ueberfuhr MA, Braun A, Wiegrebe L, Grothe B, Drexl M. Modulation of auditory percepts by transcutaneous electrical stimulation. Hear Res. 2017 Jul;350:235-43.

van de Berg R, Guinand N, Guyot JP, Kingma H, Stokroos RJ. The modified ampullar approach for vestibular implant surgery: feasibility and its first application in a human with a long-term vestibular loss. Front Neurol. 2012 Feb;3:18.

van de Berg R, Guinand N, Nguyen TA, Ranieri $\mathrm{M}$, Cavuscens S, Guyot JP, et al. The vestibular implant: frequency-dependency of the electrically evoked vestibulo-ocular reflex in humans. Front Syst Neurosci. 2015 Jan;8:255.

van de Berg R, Guinand N, Ranieri M, Cavuscens S, Khoa Nguyen TA, Guyot JP, et al. The Vestibular Implant Input Interacts with Residual Natural Function. Front Neurol. 2017 Dec;8: 644.

van de Berg R, Guinand N, Stokroos RJ, Guyot JP, Kingma $H$. The vestibular implant: quo vadis? Front Neurol. 2011 Aug;2:47.

Wall C 3rd, Kos MI, Guyot JP. Eye movements in response to electric stimulation of the human posterior ampullary nerve. Ann Otol Rhinol Laryngol. 2007 May;116(5):369-74.

Wall C 3rd, Weinberg MS, Schmidt PB, Krebs DE. Balance prosthesis based on micromechanical sensors using vibrotactile feedback of tilt. IEEE Trans Biomed Eng. 2001 Oct;48(10): 1153-61.

Wilkinson D, Zubko O, Sakel M. Safety of repeated sessions of galvanic vestibular stimulation following stroke: a single-case study. Brain Inj. 2009 Sep;23(10):841-5.

Wolter NE, Gordon KA, Papsin BC, Cushing SL. Vestibular and balance impairment contributes to cochlear implant failure in children. Otol Neurotol. 2015 Jul;36(6):1029-34.
Wuehr M, Boerner JC, Pradhan C, Decker J, Jahn $\mathrm{K}, \mathrm{Brandt} \mathrm{T}$, et al. Stochastic resonance in the human vestibular system - Noise-induced facilitation of vestibulospinal reflexes. Brain Stimul. 2018 Mar - Apr;11(2):261-3.

Wuehr M, Decker J, Schniepp R. Noisy galvanic vestibular stimulation: an emerging treatment option for bilateral vestibulopathy. J Neurol. 2017 Oct;264(S1 Suppl 1):81-6.

Wuehr M, Nusser E, Decker J, Krafczyk S, Straube A, Brandt T, et al. Noisy vestibular stimulation improves dynamic walking stability in bilateral vestibulopathy. Neurology. 2016b Jun;86(23):2196-202.

Wuehr M, Nusser E, Krafczyk S, Straube A, Brandt T, Jahn K, et al. Noise-Enhanced Vestibular Input Improves Dynamic Walking Stability in Healthy Subjects. Brain Stimul. 2016a Jan-Feb;9(1):109-16.

Xu XD, Zhang XT, Zhang Q, Hu J, Chen YF, Xu M. Ocular and cervical vestibular-evoked myogenic potentials in children with cochlear implant. Clin Neurophysiol. 2015 Aug; 126(8):1624-31.

Zhang X, Sasaki M, Sato H, Meng H, Bai RS, Imagawa $\mathrm{M}$, et al. Convergence of the anterior semicircular canal and otolith afferents on cat single vestibular neurons. Exp Brain Res. 2002 Dec;147(3):407-17.

Zhang X, Zakir M, Meng H, Sato H, Uchino Y. Convergence of the horizontal semicircular canal and otolith afferents on cat single vestibular neurons. Exp Brain Res. 2001 Sep; 140(1):1-11.

Zingler VC, Weintz E, Jahn K, Huppert D, Cny$\operatorname{rim} \mathrm{C}$, Brandt T, et al. Causative factors, epidemiology, and follow-up of bilateral vestibulopathy. Ann N Y Acad Sci. 2009 May; 1164(1):505-8.

Zingler VC, Weintz E, Jahn K, Mike A, Huppert $\mathrm{D}$, Rettinger N, et al. Follow-up of vestibular function in bilateral vestibulopathy. J Neurol Neurosurg Psychiatry. 2008 Mar;79(3):284-8. 